\title{
EL ÍNDICE DE LA VENTAJA COMPARATIVA REVELADA (VCR) ENTRE EL PERÚ Y LOS PRINCIPALES EXPORTADORES DEL MUNDO El caso de la Región Lambayeque
}

\author{
THE REVEALED COMPETITIVENESS INDEX COMPARISON BETWEEN \\ PERU AND MAIN WORLD EXPORTERS \\ The case of Lambayeque Region
}

\section{Jorge Heredia Pérez¹ y Jorge Huarachi Chávez²}

\section{RESUMEN}

El presente artículo trata acerca de la aplicación del enfoque del índice de competitividad revelada propuesto por Balassa (1965) para la Región Lambayeque, en el Perú, con la finalidad de determinar los productos competitivos de esta región. En la primera parte se presenta un marco teórico sobre competitividad, que abarca desde los primeros estudios sobre el tema hasta la competitividad sistémica. La ventaja de este método es que logra cuantificar, a través de la información que se encuentra disponible en la base datos de FAOSTAT, el grado de competitividad de un producto o un servicio de un país en función de sus valores de importación y exportación, el cual a su vez está en relación con los demás países del mundo.

Los resultados muestran que los cultivos más competitivos de la región son: las paltas, los plátanos, los mangos, los espárragos, los pimientos secos y el café. No obstante, al compararlos con otros países de América Latina como Chile y Brasil, solo los espárragos y los mangos son verdaderamente competitivos. Sin embargo, la mayor parte de los productos de exportación son commodities, por lo que las ventajas competitivas se deben mayormente al menor precio de producción, y las ventajas comparativas provienen del suelo y el clima.

Palabras claves: agroindustria, competitividad, exportación, comercio, asociatividad.

\section{ABSTRACT}

This paper presents and applies a conceptual framework to regional Competitiveness using the Index of revealed competitiveness introduced by Balassa in 1965 for the Lambayeque Region in the northern part of Peru with the end to determine the products more competitive of this region. In the first part of the article the competitiveness review is presented from the Porter approach to Systemic Competitiveness. The advantage of this method is to identify the competitiveness of the regional products and services as a function of the import and export values of the country in contrast with the same values of the other countries in the world. The FAOSTAT data is used for that purpose.

The results shown that the crop most competitive are the avocados, the bananas, mangoes, asparagus, dry chilies and coffee. Nevertheless when these products are compare with others countries such as Chile and Brazil only mangoes and asparagus are strongly competitive. However both products are considered commodities rather than value added products and its competitiveness lies in comparative advantage such as clime and soil.

Key words: Agribusiness, competitiveness, export, trade, partnership.

1. Universidad Católica Santo Toribio de Mogrovejo (Perú). Doctorando en Management Science de la Universidad Adolfo Ibáñez (Chile).<jheredia@usat.edu.pe>.

2. Universidad Católica Santo Toribio de Mogrovejo (Perú). Ph. D. en Economía Agrícola por The University of Tennessee. $<$ jhuarachi@usat.edu.pe>. 


\section{INTRODUCCIÓN}

La necesidad de las empresas por ser más eficientes y perdurar en el tiempo ha originado el estudio de las ventajas y las estrategias competitivas (Casas, 2005). El presente trabajo expone por primera vez un análisis de la competitividad regional según la teoría de la integración económica de Bela Balassa (1965), la cual está basada en el cálculo de la competitividad revelada.

La gran ventaja de este método es que logra cuantificar el grado de competitividad de un producto o un servicio de un país en función de sus valores de importación y exportación las cuales se encuentran en relación con los demás países del mundo, pues esta información sí está disponible. Existen otros métodos que miden la competitividad en función de factores internos y externos, aunque su limitación es que la información disponible no es completa, lo que impide su cálculo.

Como resultado del cálculo de la competitividad revelada para la Región Lambayeque, en el Perú, tenemos que solo $12 \%$ de la oferta exportable es competitiva, debido a ventajas comparativas como el suelo y el clima, pero que adolece de tecnología y gestión, lo que genera una posición no estable en cuanto a competitividad. Del $12 \%$ la de oferta exportable, solo $5 \%$ es altamente competitiva y, por tanto, puede impulsarse su exportación. Es importante indicar que la medición de la competitividad se realiza a lo largo del tiempo, por este motivo, el trabajo presenta una metodología para su medición periódica y su posterior comparación para implementar políticas de Estado.

Asumimos que para este estudio los resultados de la fórmula de Balassa para el Perú como país pueden ser extensivos para la Región Lambayeque, en vista de las similitudes de factores de competitividad para todas las regiones. De esta manera, en trabajos futuros se pueden encontrar factores de corrección por regiones.

Es importante indicar que este trabajo se ha realizado con datos disponibles en el portal de la FAO hasta 2005 , lo que determina la necesidad de realizar actualizaciones hasta 2008 para conocer la evolución de la competitividad.

\section{MARCO TEÓRICO}

En primer lugar, se analizarán los conceptos de competitividad en general, para luego especificar la competitividad empresarial $y$, finalmente, llegar a la competitividad agroindustrial. Con el objetivo de mostrar una revisión de los estudios sobre competitividad en las regiones del Perú, se discuten los principales estudios sobre la determinación de los factores de competitividad.

El estudio del entorno regional agroindustrial en relación con la competitividad se muestra con estadísticas recientes, las cuales permiten descubrir los factores que la afectan.

\section{La competitividad}

La literatura sobre competitividad es variada. Michael Porter fue uno de los primeros autores en aportar algunas de las principales definiciones sobre el tema, pues puso el concepto de competitividad en el centro de discusión a escala internacional a través de obras como Estrategia competitiva: técnicas para el análisis de los sectores industriales y la competencia y mediante estudios como El análisis de la cadena de valor de la empresa.

Porter propuso el concepto de «cadena de valor» para identificar formas de generar más beneficio para el consumidor y con ello obtener ventajas competitivas. Este concepto se refiere a hacer el mayor esfuerzo para lograr la fluidez de los procesos centrales de la empresa, lo cual implica una interrelación funcional basada en la cooperación.

El International Institute for Management Development (IIMD) define la competitividad como «la capacidad que tiene un país o una empresa para, proporcionalmente, generar más riqueza que sus competidores en mercados internacionales».

La Organización de Cooperación para el Desarrollo Económico (OCDE) define la competitividad como «el grado en el cual un país, bajo condiciones de mercado libres y justas, puede producir bienes y servicios que superen el test de los mercados internacionales, incrementando en forma sostenida los ingresos reales de su población». 
Según el Harvard Institute for Strategy and Competitiveness, la prosperidad de una nación depende de su competitividad, la cual se basa en la productividad con la que puede producir bienes y servicios. Políticas macroeconómicas sólidas e instituciones políticas y legales estables son condición necesaria aunque no suficiente para asegurar la prosperidad económica. También sostiene que la competitividad tiene sus raíces en los fundamentos microeconómicos, el nivel tecnológico y las estrategias de las empresas, así como en la calidad del ambiente empresarial en el que las compañías compiten. Entender los fundamentos microeconómicos de la competitividad es fundamental para la política económica nacional.

La Comisión Económica para América Latina y El Caribe (Cepal) considera que «la competitividad auténtica debe estar basada en la incorporación de tecnología y el uso renovable de los recursos naturales, concepción que contrasta con la competitividad espuria que se basa en la explotación de los recursos humanos y naturales».

\section{Competitividad sistémica}

Recientemente, y como fruto de un debate dentro de la OCDE, ha sido propuesto un modelo que aborda el tema de competitividad de un país desde una perspectiva sistémica. Este modelo, conocido como «competitividad sistémica», plantea cuatro niveles para explicar los elementos básicos que permiten competir a las empresas en un país determinado en los siguientes niveles: meta, macro, meso y micro.

\section{La competitividad del National Competitiveness Council (NCC)}

Según el National Competitiveness Council (2006), la competitividad de una nación es la habilidad para ganar progresivamente participación de mercado y mejorar el estándar de vida para todos.

\section{Competitividad agroindustrial}

Piedra et ál. (s/f) determina que la agroindustria cubre un espectro amplio de productos y servicios, que van desde productos genéricos hasta productos lis- tos para consumir. Abbott y Bredahl (1994) han identificado los productos genéricos no diferenciados, los productos primarios sin diferenciar, los productos semi-procesados y los productos listos para consumo como las cuatro economías de la agricultura. Esta gran diversidad requiere que un análisis de la competitividad agroindustrial tome en cuenta no solo los factores que afectan los costos de producción, sino también aquellos factores que afectan la diferenciación de los productos. Los estudios que se centren en productos genéricos deberían poner un mayor énfasis en la importancia del desarrollo de estrategias para disminuir los costos. Por el contrario, los estudios interesados en la competitividad de productos altamente procesados listos para el consumo deben incorporar los efectos de estrategias que afectan la diferenciación del producto y la empresa o el sector.

\section{La competitividad agroindustrial del Strategic Management School}

Según una publicación del Strategic Management School de 1997, el concepto de competitividad se explica en función del objeto analizado. Es decir, lo que constituye el esquema conceptual de la competitividad de una nación es distinto de la competitividad de las agroindustrias. La competitividad agroindustrial es la habilidad para crear beneficio y entregar valor por liderazgo en costos y/o diferenciación del producto.

El liderazgo en costos está más relacionado con productos commodities o indiferenciados en los cuales el único beneficio para el cliente es un precio menor. Algunas fuentes de reducción de costos son: la optimización de los costos variables, la optimización de inventarios, las economías de escala y la disminución de los costos de transacción. Entonces, para analizar la diferenciación del producto se habla en términos de valor percibido por el cliente. Es decir:

Valor percibido por el cliente = Beneficios percibidos $/$ Precio

En los productos agrícolas la principal fuente de beneficio percibido es la biotecnología, la cual permite crear beneficios diferenciales a productos no diferenciados; por ejemplo, productos con mejoramiento nutricional y de mejor calidad. 


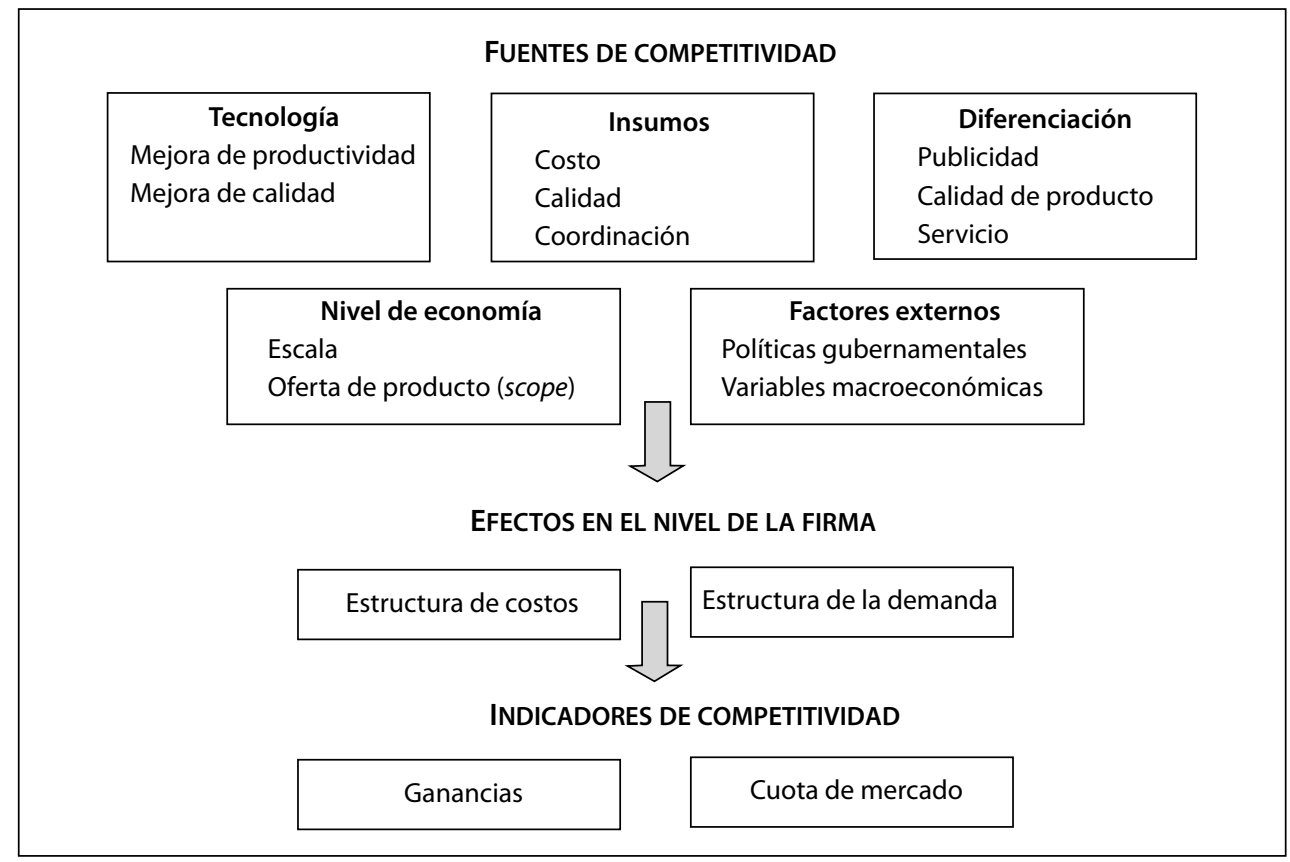

Fuente: Piedra et ál. (s/f).

Gráfico 1

Marco conceptual para evaluar la competitividad

\section{Una definición holística de competitividad}

Según Rainer (1994), la competitividad es un concepto relativo no absoluto, pues depende de la posición en que se esté como cliente (valor para los clientes) o como accionista (valor para los accionistas). El gráfico 2 también muestra que la capacidad financiera puede determinar la posibilidad de actuar y reaccionar dentro de un ambiente competitivo. Las perso- nas y la tecnología son necesarias para el cambio de posición competitiva. La sostenibilidad de la competitividad que se da existe en la medida que estos factores estén en equilibrio.

La posición competitiva de la empresa se puede ver en un mapa competitivo que permitirá determinar las brechas que se deben superar para cambiar estratégicamente su posición competitiva.

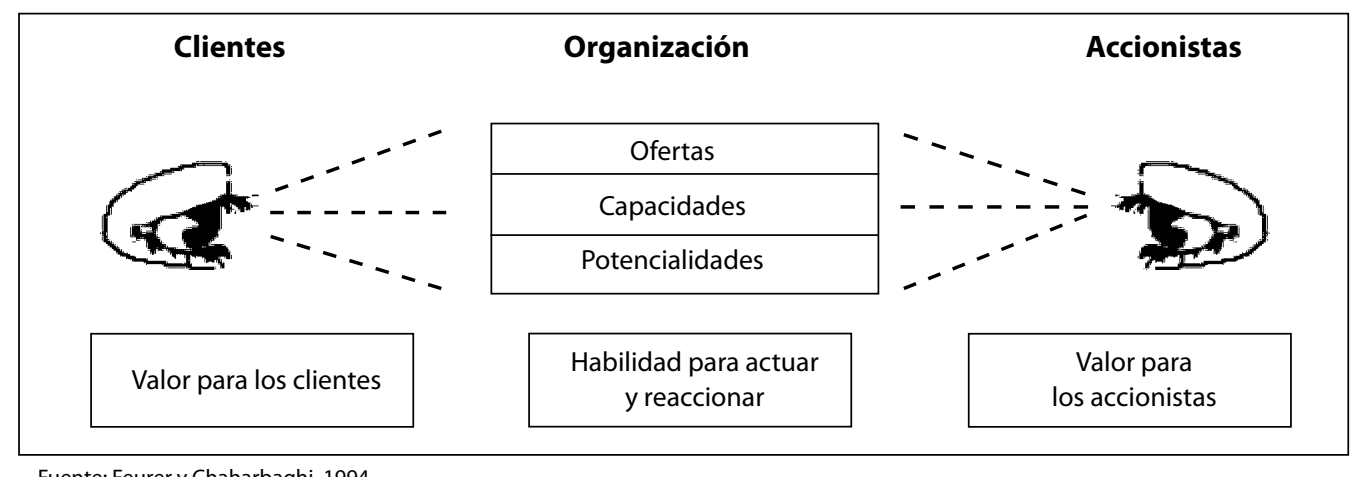

Fuente: Feurer y Chaharbaghi, 1994. 


\section{Determinantes de la competitividad}

Porter resume su modelo en el llamado «diamante nacional de competitividad», el cual presenta cuatro determinantes de la competitividad nacional que forman el entorno en que compiten las empresas locales y de los cuales depende la creación de las ventajas competitivas.

\section{Los clusters como generadores de competitividad}

Según Ketels (2007), los clusters son grupos activos de empresas, sector público y entidades relacionadas que realizan actividades de colaboración con el objetivo de mejorar la competitividad, especialmente de un grupo de actividades económicas interconectadas en una región geográfica específica.

La Corporación Andina de Fomento (CAF) ha desarrollado el Programa de Apoyo a la Competitividad (PAC), el cual establece las siguientes líneas de acción para la mejora de la competitividad:

- Desarrollo de clusters y capacidades productivas y comerciales.

- Promoción de la capacidad emprendedora.

- Mejoramiento del clima de negocios.

El programa PAC también ha realizado un diagnóstico sobre el cluster, en el cual se indica:

Los clusters en los países de la región son, en general, escasos, débiles e incipientes; se basan en recursos natu- rales y carecen de un clima de negocios apropiados para su desarrollo. Asimismo, generan productos de bajo valor agregado, utilizan mano de obra poco calificada y cuentan con escasas empresas especializadas vinculadas con ellos. Existen instituciones públicas y privadas que apoyan a estos clusters, pero rara vez ello forma parte de un esfuerzo coordinado que responde a una estrategia nacional o regional de desarrollo. Sin embargo, hay casos de clusters que poseen gran potencial de desarrollo que vale la pena con el apoyo de programas y políticas públicas, dirigidas a mejorar el clima de negocios en lo relacionado con la infraestructura de transporte, tecnologías, niveles de investigación, trámites burocráticos, programas educativos y otros (CAF, 2007).

\section{La competitividad peruana según el International Institute for Management Development}

En mayo de 2008 el IIMD en alianza con Centrum, la escuela de negocios de la Pontificia Universidad Católica del Perú, realizó un cálculo de la competitividad del Perú que se muestra en el cuadro 1, el cual fue publicado como parte del índice de competitividad mundial para el año 2008. En esa publicación Stéphane Garelli, director del IIMD's World Competitiveness Center, indica:

En 2008, EE. UU. lideró el ranking de competitividad, seguido de Singapur y Hong Kong, quienes mantuvieron sus posiciones respecto al año precedente. A nivel latinoamericano, el ranking fue liderado por Chile (puesto 26 en el global), seguido de Perú (puesto 35 en el global), superando a países como Colombia (puesto 41), Brasil (puesto 43) y México (puesto 50).

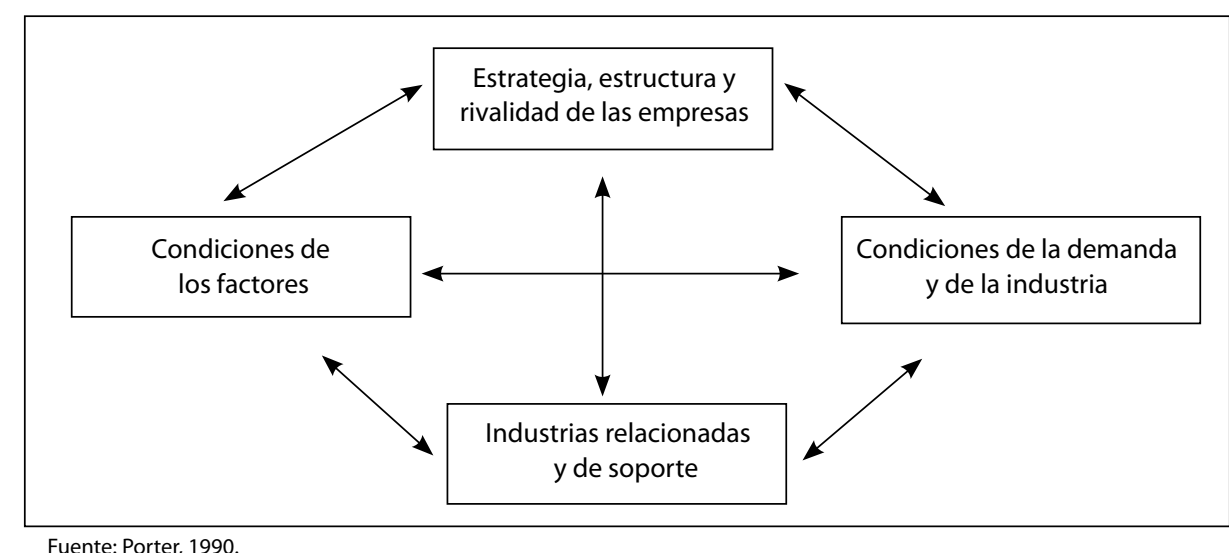

Gráfico 3

Modelo del diamante nacional de competitividad 
Cuadro 1. Panorama de la competitividad del Perú: aspectos positivos y negativos

Peruvian competitiveness landscape

\begin{tabular}{cll} 
Improvements & Value & Position \\
Mejores resultados & Valor & Posición \\
\hline
\end{tabular}

Labor force \% of population

Fuerza laboral como porcentaje de la población

$73,97 \quad 1$

Real GDP Growth per capita \% change, based on national currency in constant prices

Crecimiento del PBI real per cápita como porcentaje de cambio, en moneda nacional a precios constantes

Total public expenditure on education \% of GDP

Gasto público total en educación, como porcentaje del PBI

11,050000

Real GDP Growth \% change, based on national currency in constant prices

Crecimiento del PBI real en porcentaje, en moneda nacional a precios constantes

Collected total tax revenues \% of GDP

Recaudación total por impuesto a la renta como porcentaje del PBI

Female labor force $\%$ of total labor force

Fuerza laboral femenina como porcentaje de la fuerza laboral total

\begin{tabular}{lll} 
PBI & 14,95 & 7 \\
\hline al & 52,27 & 2 \\
\hline
\end{tabular}

Cost-of-living index. Index of a basket of goods \& services in major cities, including housing (New York City = 100)

Índice del costo de vida. Índice de una canasta de bienes y servicios de las principales ciudades, incluido

alquiler (Ciudad de Nueva York $=100$ )

Working hours. Average number of working hours per year

Horas trabajadas. Promedio del número de horas trabajadas por año

11,05

Management of public finances over the next two years is likely to improve (Survey)

La gestión de las finanzas públicas durante los dos próximos años es probable que mejore (encuesta)

Relocation of $R \& D$ facilities is not a threat to the future of your economy (Survey)

Relocalización de las instalaciones de I\&D no es una amenaza para el futuro de su economía (encuesta)

Employment \% of population

Empleo porcentaje de la población empleada

Relocation of production is not a threat to the future of your economy (Survey)

La relocalización de la producción no es una amenaza para el futuro de la economía (encuesta)

Central bank policy has a positive impact on economic development (Survey)

La política del Banco Central de Reserva del Perú tiene impacto positivo en el desarrollo económico (encuesta)

\begin{tabular}{|c|c|c|}
\hline $\begin{array}{l}\text { Declines } \\
\text { Peores resultados }\end{array}$ & $\begin{array}{l}\text { Value } \\
\text { Valor }\end{array}$ & $\begin{array}{l}\text { Position } \\
\text { Posición }\end{array}$ \\
\hline $\begin{array}{l}\text { Mobile telephone subscribers. Number of subscribers per } 1000 \text { inhabitants } \\
\text { Suscriptores de telefonía móvil. Número de suscriptores por } 1000 \text { habitantes }\end{array}$ & 309,10 & 53 \\
\hline $\begin{array}{l}\text { Total health expenditure \% of GDP } \\
\text { Gasto total en salud porcentaje del PBI }\end{array}$ & 4,00 & 50 \\
\hline $\begin{array}{l}\text { Overall productivity (PPP). Estimates: GDP (PPP) per person employed, US\$ } \\
\text { Productividad total (PPP). Estimado: PBI (PPP) por persona empleada, US\$ }\end{array}$ & 12999,00 & 51 \\
\hline $\begin{array}{l}\text { Labor productivity (PPP). Estimates: GDP (PPP) per person employed per hour, US\$ } \\
\text { Productividad laboral (PPP). Estimado: PBI (PPP) por persona empleada por hora, US\$ }\end{array}$ & 6,02 & 51 \\
\hline $\begin{array}{l}\text { Investment risk. Euromoney country credit-worthiness scale from 0-100 } \\
\text { Riesgo de inversión. Calificación Euromoney de países en una escala de 0-100 }\end{array}$ & 49,63 & 50 \\
\hline $\begin{array}{l}\text { Total expenditure on } R \& D \% \text { of GDP } \\
\text { Gasto total en I\&D porcentaje del PBI }\end{array}$ & 0,15 & 52 \\
\hline $\begin{array}{l}\text { Dependency ratio. Population under } 15 \text { and over } 64 \text { years old, divided by active population (15 to } 64 \text { years) } \\
\text { Ratio de dependencia. Población por debajo de los } 15 \text { y por encima de los } 64 \text { años, entre la población activa } \\
\text { (15 a } 64 \text { años) }\end{array}$ & 57,80 & 50 \\
\hline $\begin{array}{l}\text { GDP (PPP) per capita. Estimates; US\$ per capita at purchasing power parity } \\
\text { PBI (PPP) per cápita; US\$ per cápita expresado en poder de paridad de compra }\end{array}$ & 7404,00 & 48 \\
\hline
\end{tabular}

Fuente: World Competitiveness Center-IIMD y Centrum-PUCP, 2008. 


\section{ANÁLISIS DEL SECTOR AGROINDUSTRIAL DE LA REGIÓN LAMBAYEQUE}

Para el análisis de esta sección se tomará como referencia el Plan Estratégico Regional Exportador de la Región Lambayeque publicado por Málaga-Webb y Asociados en el año 2004.

La Región Lambayeque está localizada en la costa noroccidental del territorio nacional, abarca una superficie de 14 249,30 kilómetros cuadrados, es decir, $1,1 \%$ de la superficie territorial del Perú. Limita por el norte con el departamento (o región) de Piura, por el sur con La Libertad, por el este con Cajamarca y por el oeste con el océano Pacífico.

Políticamente, la región está constituida por tres provincias y 38 distritos. Las tres provincias son Chiclayo, Ferreñafe y Lambayeque. Presenta tres tipos de territorio: la costa, que comprende la mayor parte y se caracteriza por extensos desiertos y tablazos vecinos al mar; la sierra que comprende los flancos occidentales de la cordillera de los Andes, de topografía muy accidentada con algunos valles interandinos entre 2000 y 4000 m. s. n. m.; y la selva, que corresponde a una pequeña zona en la cuenca del río Huancabamba, en el distrito de Cañaris.

Sin embargo, la característica del Perú como un país altamente centralizado condiciona el aporte redu- cido que cada una de las regiones del interior hace a la formación de la riqueza nacional. En este caso, según el Instituto Nacional de Estadística e Informática (INEI) la Región Lambayeque solo aporta 3,89\% del producto bruto interno (PBI) peruano, lo que la ubica como la quinta economía más grande del Perú después de Lima, Arequipa, La Libertad y Piura.

Las principales actividades que sustentan la economía lambayecana son: la agricultura, la industria manufacturera y los servicios, que en conjunto aportan $96,5 \%$ al producto bruto interno regional. Estos sectores absorben la mayor proporción de la población económicamente activa ocupada. El cuadro 2 refleja el PBI regional por sectores económicos.

Respecto de los ingresos fiscales recaudados en la región que se muestran en el cuadro 3, estos ocupan el séptimo lugar con mayor recaudación, pues se ubican después de Lima-Callao, Arequipa, Piura, La Libertad, Ica y Cusco.

Cuadro 3. Ingresos recaudados por la Sunat, 2002

\begin{tabular}{|l|c|}
\hline \multicolumn{1}{|c|}{ Tipo de impuesto } & $\begin{array}{c}\text { Recaudación } \\
\text { (en millones de soles) }\end{array}$ \\
\hline Internos & 110 \\
\hline Proporción regional / nacional & 0,6 \\
\hline Total nacional (internos) & 18734 \\
\hline
\end{tabular}

Nota. Tributos internos: impuesto a la renta, producción y consumo, y otros.

Fuente: Superintendencia Nacional de Administración Tributaria (Sunat).

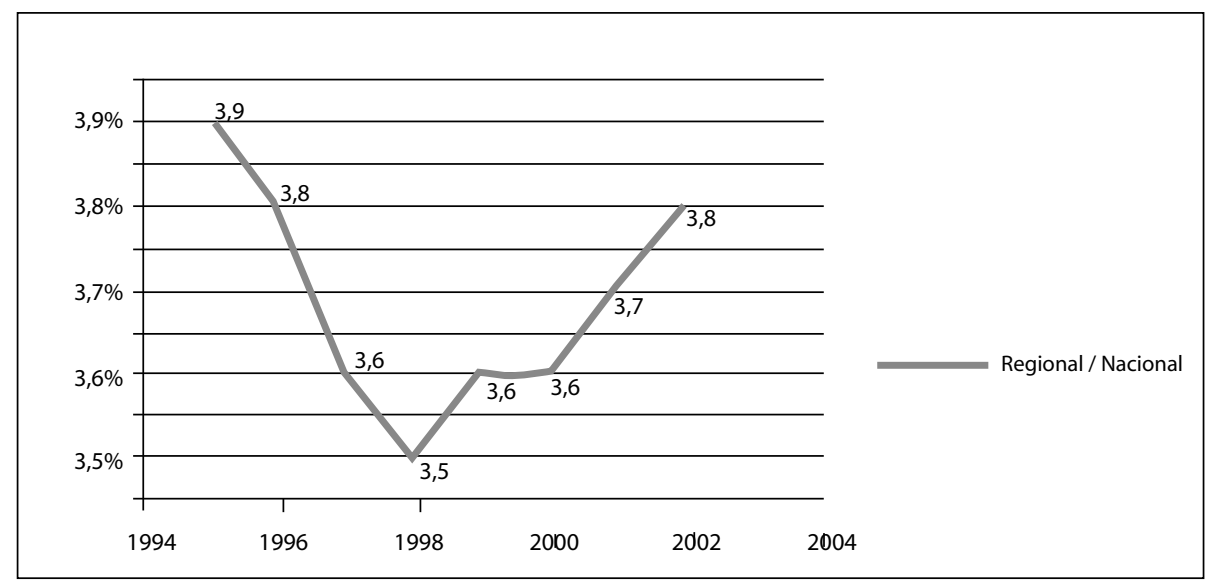

Fuente: INEI. 


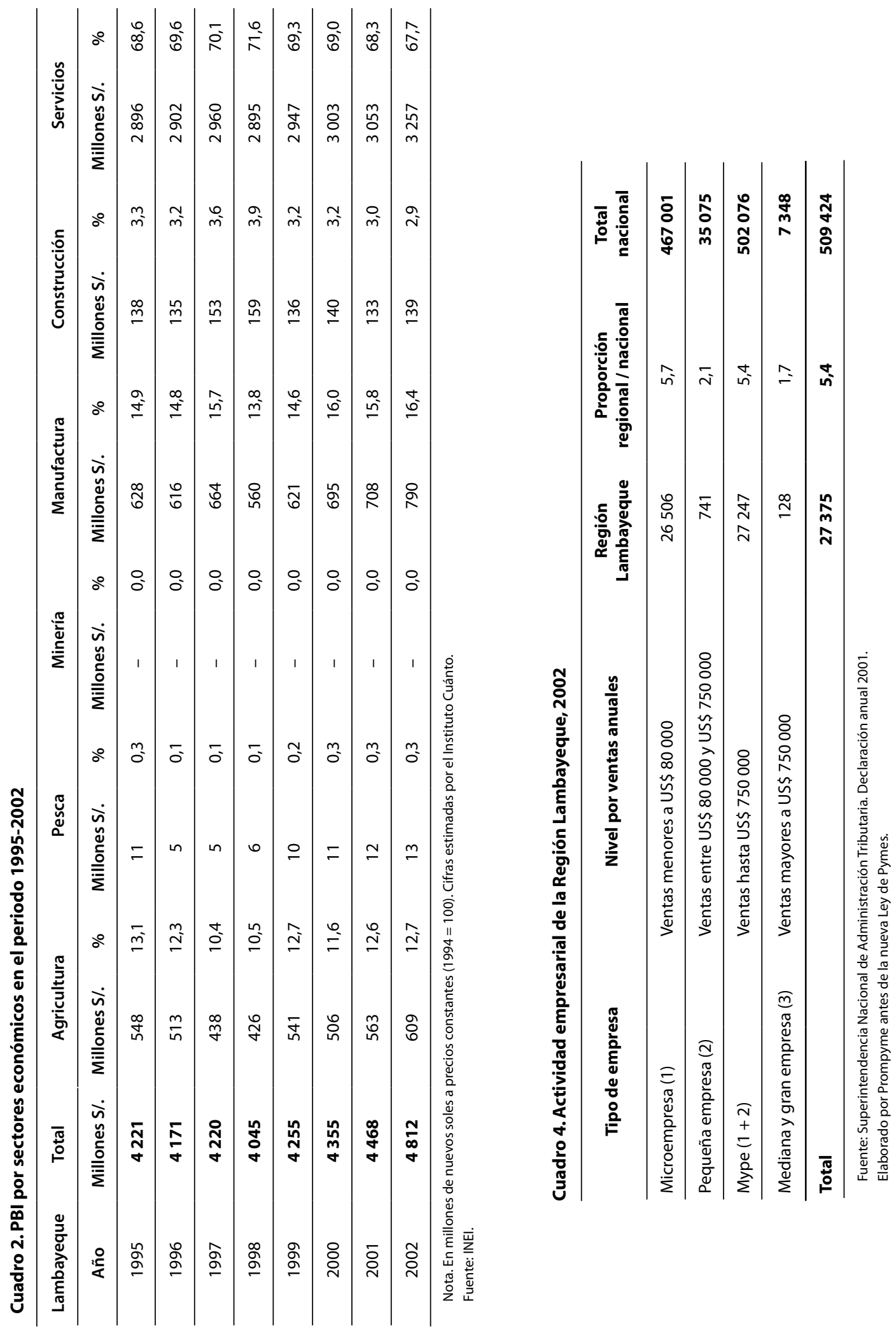


La actividad empresarial de la Región Lambayeque se refleja en el cuadro 4 , en donde se observa que más de $96,83 \%$ de las empresas pertenecen al nivel de microempresas, $2,71 \%$ son pequeñas empresas y solo $0,47 \%$ se encuentran dentro de las medianas y las grandes empresas.

En el cuadro 5 se enumeran los principales productos exportados por la Región Lambayeque; el café sin descafeinar, los espárragos, los frijoles desvainados, los demás frijoles y las demás hortalizas.
Asimismo, en el cuadro 6 se muestran los principales mercados de destino de los seis productos más exportados por la Región Lambayeque a través de las principales empresas exportadoras lambayecanas, las cuales se presentan en el cuadro 7. De esta manera, los datos y las características de la economía de la Región Lambayeque, muestran que esta región todavía tiene un largo camino que recorrer para aprovechar mejor las oportunidades que ofrece el mercado exterior, así como para explorar al máximo sus potencialidades.

\section{Cuadro 5. Exportaciones (FOB) por producto de la Región Lambayeque}

\begin{tabular}{|c|c|c|}
\hline Descripción arancelaria & Total en US\$ & $\%$ \\
\hline Café sin descafeinar, sin tostar & 51930337 & 49,44 \\
\hline Frijoles desvainados, preparados o conservados, sin congelar & 9339128 & 8,89 \\
\hline Los demás frejoles, excepto para siembra & 6297514 & 6,00 \\
\hline Frutos de los géneros capsicum o pimenta, secos, triturados o pulverizados & 3940426 & 3,75 \\
\hline Frijoles (frejoles, porotos, alubias, judías) (Vigna spp., Phaseolus spp.) cocidos o congelados & 2162679 & 2,06 \\
\hline Cebollas preparadas o conservadas en vinagre o ácido acético & 2040198 & 1,94 \\
\hline Las demás hortalizas preparadas o conservadas sin congelar & 1945151 & 1,85 \\
\hline Aceites esenciales de limón & 1872437 & 1,78 \\
\hline Jugos de cualquier otro agrio (cítrico) & 1376727 & 1,31 \\
\hline Frijoles de la especie Vigna mungo $(L)$ hepper o Vigna radiata $(L)$ wilczek, excepto para la siembra & 651282 & 0,62 \\
\hline Mangos preparados o conservados & 627936 & 0,60 \\
\hline Manteca de cacao con índice de acidez expresado en ácido oleico $<=1,0 \%$ & 592700 & 0,56 \\
\hline Jugo de «maracuyá» (parchita) o Passiflora edulis & 525568 & 0,50 \\
\hline Demás frutas/frutos y demás partes comestibles de plantas, preparados o conservados de otro modo & 424171 & 0,40 \\
\hline Manteca de cacao con índice de acidez expresado en ácido oleico $>1,0 \%$, pero $<=1,65 \%$ & 346340 & 0,33 \\
\hline Cacao en polvo sin adición de azúcar ni otro edulcorante & 333000 & 0,32 \\
\hline Alcohol etílico sin desnaturalizar con grado alcohólico volumétrico $>=80 \%$ de volumen & 268200 & 0,26 \\
\hline Mangos y mangostanes, frescos o secos & 257537 & 0,25 \\
\hline Alcachofas (alcauciles) preparadas o conservadas, sin congelar & 217981 & 0,21 \\
\hline Los demás frijoles preparados o conservados, sin congelar & 156127 & 0,15 \\
\hline Extracto de malta & 146698 & 0,14 \\
\hline Frijol común (Phaseolus vulgaris), excepto para siembra & 144739 & 0,14 \\
\hline Pasta de cacao total o parcialmente desgrasada & 144600 & 0,14 \\
\hline Maíz blanco (maíz gigante del Cusco) & 130433 & 0,12 \\
\hline Ajos, frescos o refrigerados & 123245 & 0,12 \\
\hline Demás frutas y otros frutos, sin cocer o cocidos en agua o vapor, sin azúcar o edulcorante, congelados & 117731 & 0,11 \\
\hline
\end{tabular}

Fuente: Comisión para la Promoción de Exportaciones (Prómpex). Ubigeo de aduanas.

Elaboración de Málaga-Webb \& Asociados. 
Cuadro 6. Principales mercados de destino según producto exportado

\begin{tabular}{|c|c|}
\hline Productos más importantes & Principal destino \\
\hline Café sin descafeinar, sin tostar & Alemania \\
\hline Espárragos preparados o conservados, sin congelar & España \\
\hline Frijoles desvainados, preparados o conservados, sin congelar & Estados Unidos \\
\hline Los demás frejoles, excepto para siembra & Portugal \\
\hline Las demás hortalizas (incluso silvestres), aunque estén cocidos en agua o vapor, o congeladas & Estados Unidos \\
\hline Frutos de los géneros capsicum o pimenta, secos, triturados o pulverizados & Estados Unidos \\
\hline
\end{tabular}

Cuadro 7. Exportaciones (FOB) por empresas de la Región Lambayeque

\begin{tabular}{lrr}
\hline \multicolumn{1}{c}{ Razón social de la empresa } & FOB en US\$ & $\%$ \\
\hline Perales Huancaruna S. A. C. & 42101530 & 40,1 \\
Agro Industrias Backus S. A. & 22668009 & 21,6 \\
Procesadora S. A. C. & 10175426 & 9,7 \\
Gandules INC S. A. C. & 6245114 & 5,9 \\
Corporacion Miski S. A. & 3332200 & 3,2 \\
Percof S. A. C. & 3276557 & 3,1 \\
Antonio Rinaldi S. A. & 3274611 & 3,1 \\
Sun Packers S. R. Ltda. & 2590085 & 2,5 \\
Procesadora Frutícola S. A. & 1597010 & 1,5 \\
Conservas y Alimentos S. A. & 1416640 & 1,3 \\
Consorcio Empresarial AGNAV S. A. & 1388402 & 1,3 \\
Pronatur E. I. R. L. & 1229901 & 1,2 \\
Asociación de Productores Agropecuarios Rodríguez de Mendoza & 1140366 & 1,1 \\
Otros & 4594186 & 4,4 \\
\hline TOTAL & $\mathbf{1 0 5 0 3 0 0 3 7}$ & $\mathbf{1 0 0 , 0}$ \\
\hline Fuente Pronp. & &
\end{tabular}

Fuente: Prómpex. Ubigeo de aduanas.

Elaboración de Málaga-Webb \& Asociados sobre la base de la Clasificación Internacional Industrial Uniforme (CIIU).

\section{ANÁLISIS DE FORTALEZAS Y DEBILIDADES}

\section{Ventajas de la Región Lambayeque}

Lambayeque ha sido definida por un estudio de la consultora Málaga-Webb \& Asociados como una región tradicional que se caracteriza por ser mucho más dispersa que progresista. Los indicadores oscilan alrededor de la media y tienden a un mayor índice de potencialidades y poco desarrollo exportador $y$ empresarial.

Los indicadores sociales y de infraestructura también son mayores que el promedio. Esto podría indicar que la Región Lambayeque puede tener en el mediano plazo un mayor desarrollo exportador y empresarial. 
Como resultado de las entrevistas a empresarios y autoridades se definieron las siguientes ventajas como las más importantes:

- Lambayeque es la segunda región, después de Ica, que ha entendido la importancia de vender antes que producir.

- Cuenta con $45 \%$ de su red vial asfaltada (frente a $13 \%$ en el país), la cual comunica $86 \%$ de sus distritos (en el Perú, solo $22,6 \%$ de distritos están intercomunicados mediante vía asfaltada), lo que refleja en términos relativos una mayor capacidad de acceso y menor tiempo requerido para comunicarse en comparación con el resto del país.

- Tiene una tradición en el uso de la siembra por contrato, y, pese a los costos que implica para los procesadores la contratación de varios acopiadores, el sistema ha funcionado y ha permitido mantener niveles de empleo importantes en esta actividad productiva en la Región Lambayeque.

- La apuesta por el mercado exterior es una forma de luchar contra la pobreza. La producción para la exportación genera empleos sostenibles y garantiza el crecimiento económico de la región.

\section{Debilidades de la Región Lambayeque}

Como resultado de las entrevistas a empresarios y autoridades, se definieron las siguientes debilidades como las más importantes:

- Los empresarios lambayecanos no tienen un mercado definido o un canal de comercialización claro para sus productos.

- No hay estudios sobre el mercado internacional de los productos «estrella» para la región. Por lo menos, no son conocidos por los productores y muchas de las inversiones se hacen sin tener acceso a este tipo de información.

- Para la mayoría de los empresarios sí hay mercado, de esta manera se reduce el efecto de la carencia de los otros factores.
- Hay poco dinamismo en las autoridades del gobierno central para facilitar el quehacer empresarial.

- Existen muchos sobrecostos que asumen los empresarios como consecuencia de la demora o el poco accionar de las entidades públicas (por ejemplo, el tiempo en otorgar autorizaciones para el ingreso de semillas o la creación de nuevas inspecciones, entre otros).

- Falta otorgar el poder necesario a las autoridades regionales para que puedan tomar decisiones en el momento oportuno.

- Es difícil pensar en que los empresarios se asocien porque tienen niveles educativos diferentes, lo que los hace más desconfiados y tener temor a ser engañados.

- En la Región Lambayeque no hay agroindustriales que tengan una filosofía de trabajo basada en que todos ganen, es decir, que productores, acopiadores y procesadores se beneficien a la vez o por la misma operación productiva.

- Se han reportado abusos de parte de algunos agroindustriales exportadores, quienes nunca han pagado el precio justo e inclusive a veces no pagan.

- Lo que se requiere es transferencia de tecnología, es decir, manejo de cultivos, riego computarizado y mejoramiento de espacios, entre otros.

- A pesar de la falta de acceso al crédito, los agricultores que se han desarrollado lo han hecho con capital propio, aunque esto les haya generado limitaciones.

- El empresariado regional cree que debe mantenerse la condición privada del Instituto de Desarrollo Agrario de Lambayeque.

- Hace falta apoyo para poder formular y desarrollar proyectos nuevos.

- La magnitud de las exportaciones de Lambayeque, si bien casi se duplicó entre 1996 y 2002, no muestra, como en el caso de la producción, un crecimiento sostenido.

- Las tasas de fluctuación de las exportaciones han sido bastante pronunciadas con fuertes subidas 
y bajadas en años consecutivos debido a que las empresas no conocen bien el mercado y no cuentan con mercados de destino definidos, ni compradores fijos para sus productos.

- La comparación entre la producción agrícola de la Región Lambayeque y los productos exportados por la región, revela que no toda la producción exportada por la región es producida en ella.

- En vista de que el puerto más cercano a Chiclayo es el de Paita, en la Región Piura. El exportador lambayecano debe contratar a alguna agencia aduanera localizada en Paita para que se encargue de hacer los trámites correspondientes en la Aduana y concretar la operación de exportación, pues estas agencias no cuentan con sucursales en Chiclayo.

\section{METODOLOGÍA Y RESULTADOS DE LA INVESTIGACIÓN}

Como se ha señalado, esta investigación tiene como objetivo evaluar la competitividad agroindustrial de la Región Lambayeque; de manera que para establecer algunas hipótesis primero se formularon las siguientes preguntas básicas:

- ¿Es la agroindustria de la Región Lambayeque competitiva?

- ¿Existen productos más competitivos que otros?

- ¿Con qué método podemos medir la competitividad agroindustrial de la región?

Preliminarmente, se puede determinar que la región posee un grupo de productos agroindustriales competitivos, los cuales son pocos en relación con todo su potencial exportador. Además, se puede establecer que existen factores internos y externos que limitan la competitividad de la región.

Para abordar el estudio se analizaron tres métodos para medir la competitividad agroindustrial de una determinada región económica. A continuación se muestra la ventaja y la desventaja de cada método, lo que permitió elegir el tercer método como el adecuado para el desarrollo de esta investigación.

1) Medición de la competitividad por medio de los factores. Este método usa técnicas estadísticas, analiza una serie de variables y encuentra a los clusters de las variables que expliquen la competitividad (Casas, 2005). Su principal inconveniente es que en la Región Lambayeque no hay información completa para realizar un análisis estadístico significativo.

2) Medición de la competitividad basada en la teoría económica del incremento de la productividad del sector agroindustrial. Este método presenta el mismo inconveniente, la falta de información sobre las distintas variables que inciden en la competitividad.

3) Medición de la competitividad por medio de la teoría del comercio internacional (Balassa, 1979). A través de este método el comercio internacional revela el grado de competitividad de un producto. Se escogió esta metodología de medición también porque la información requerida está disponible en la Food and Agriculture Organization of the United Nations (FAO).

\section{Cálculo de la competitividad revelada}

Con la finalidad de medir el nivel de competitividad de los cultivos de la Región Lambayeque y del Perú se utilizará el índice de competitividad revelada de Bela Balassa. Este índice es aceptado por la Comunidad Europea en comparación con otros métodos de cálculo como los modelos matemáticos.

La ventaja de su aplicación radica en que usa información del comercio internacional para determinar el grado de competitividad que tiene un producto de un país determinado. Balassa (1965) acuñó el término de «índice de ventaja comparativa revelada» (IVCR) con el fin de indicar que las ventajas comparativas entre naciones pueden ser reveladas por el flujo del comercio de mercancías, por cuanto el intercambio real de bienes refleja los costos relativos y también las diferencias que existen entre los países, no necesariamente por factores de mercado. La construcción del índice propuesto por Balassa es el siguiente: 


$$
I V C R=\frac{\frac{X_{a}^{i}}{X_{w}^{i}}}{\frac{X_{a}^{t}}{X_{w}^{t}}}
$$

\section{Donde:}

$X$ : Representa las exportaciones.

$i$ : Un producto identificado por su código arancelario.

$a \quad$ : El país sujeto de análisis.

$t \quad$ : El total de productos exportados por dicho país.

$w$ : Un conjunto de países, el cual es generalmente utilizado en el mundo.

$X_{a}^{i}$ : Las exportaciones de un producto (i) por parte del país $(a)$.

$X_{w}^{i}$ : Las exportaciones de un producto $(i)$ por parte del mundo $(w)$.

$X_{a}^{t}$ : Las exportaciones totales $(t)$ por parte del país $(a)$.

$X_{w}^{t}$ : Las exportaciones totales $(t)$ por parte del mundo $(w)$.
Con la finalidad de calcular la ventaja comparativa neta se consideran las importaciones. Entonces, la fórmula del índice de ventajas competitivas revelada $(I V C R)$ queda definido de la siguiente manera:

$$
I V C R=V C E-V C I
$$

Donde:

$V C E$ : Ventaja competitiva de exportación.

$V C I$ : Ventaja competitiva de importación.

\section{Presentación de los resultados}

A continuación se presenta el cálculo del IVCR para el Perú —el cual se asume que es igual al de la región norte del Perú- respecto de los cultivos de exportación en la agroindustria. Para estos resultados se han tomado los datos de la FAO.

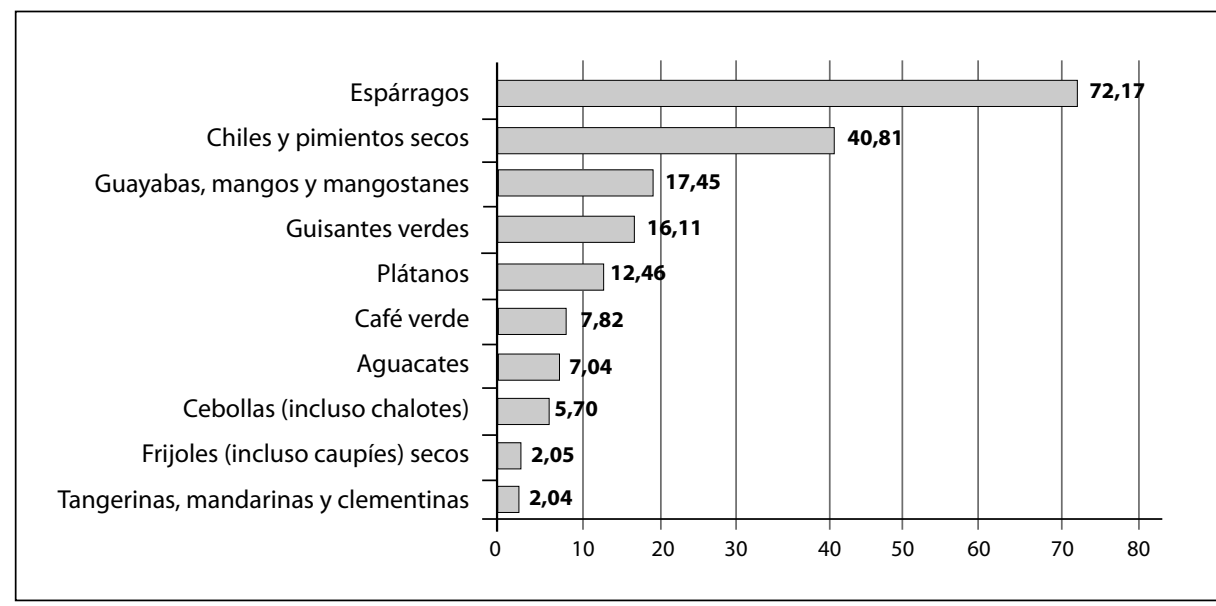

Fuente: Elaboración propia sobre la base de las estadísticas de FAOSTAT, 2005.

Gráfico 5

Los diez primeros productos agroindustriales del Perú con mayor IVCR en 2005 


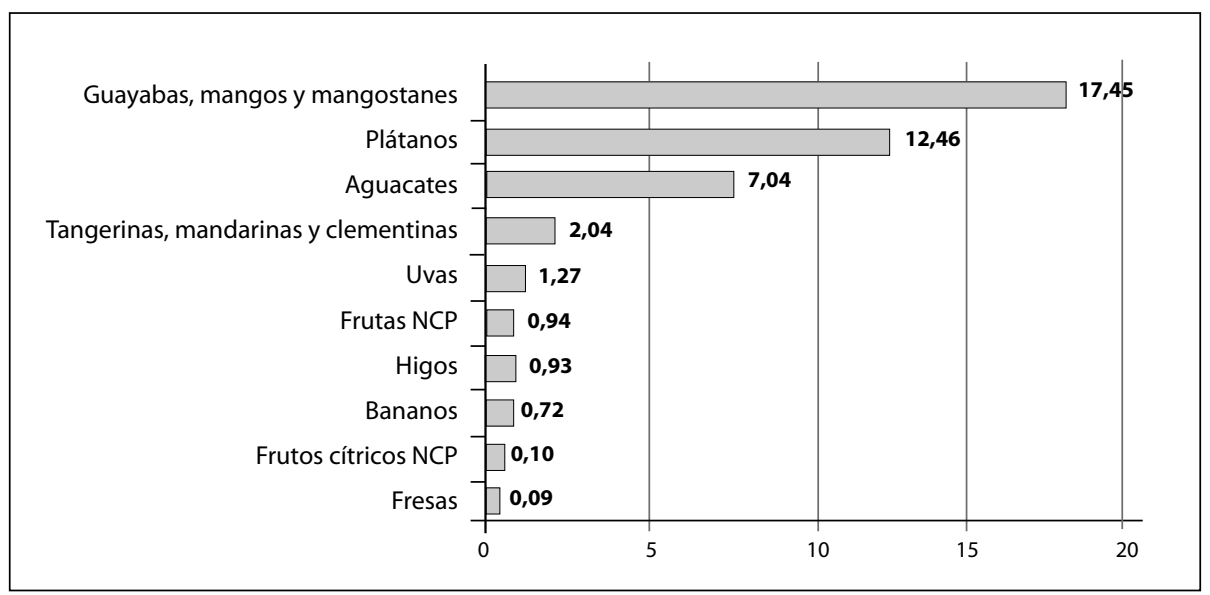

Fuente: Elaboración propia sobre la base de las estadísticas de FAOSTAT, 2005.

Gráfico 6.

Los primeros productos agroindustriales del Perú con mayor IVCR en 2005, sector frutas

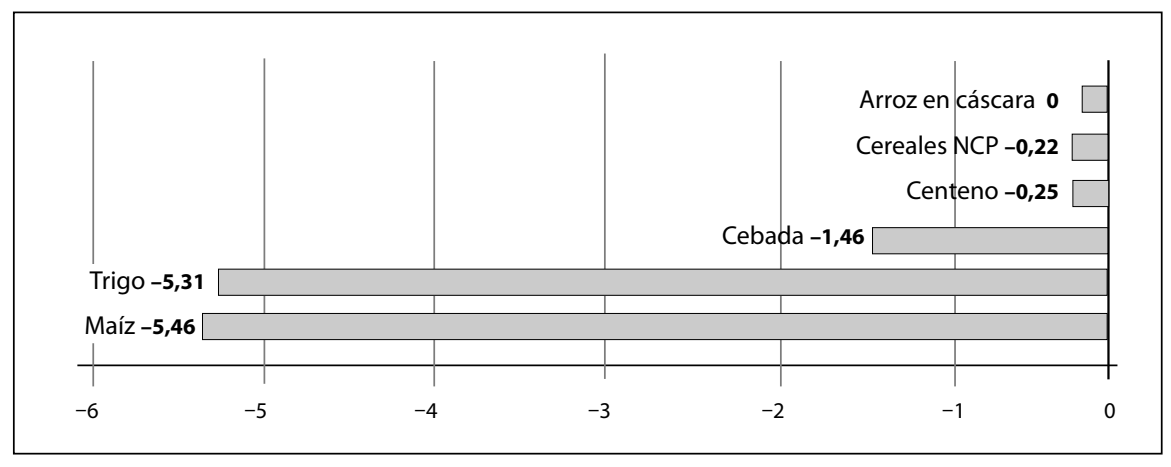

Fuente: Elaboración propia sobre la base de las estadísticas de FAOSTAT, 2005.

Gráfico 7

Los primeros productos agroindustriales del Perú con mayor IVCR en 2005, sector cereales

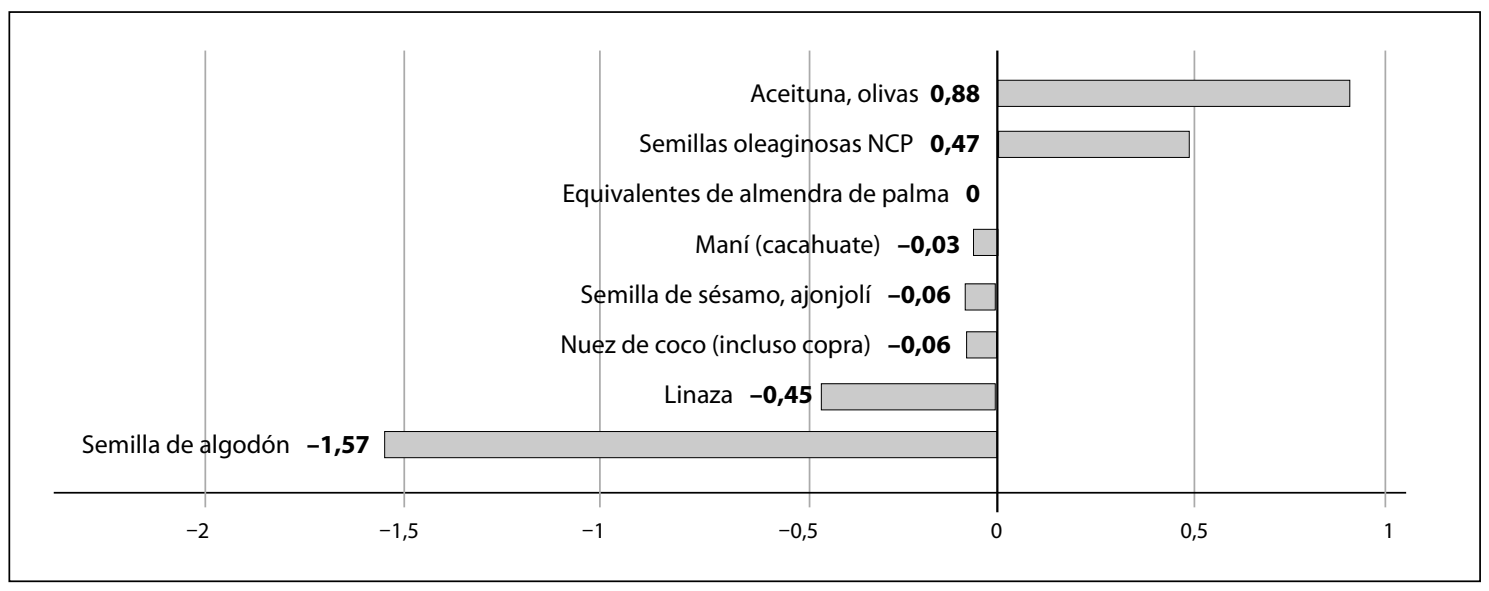

Fuente: Elaboración propia sobre la base de las estadísticas de FAOSTAT, 2005.

Gráfico 8

Los primeros productos agroindustriales del Perú con mayor IVCR en 2005, sector oleaginosos 


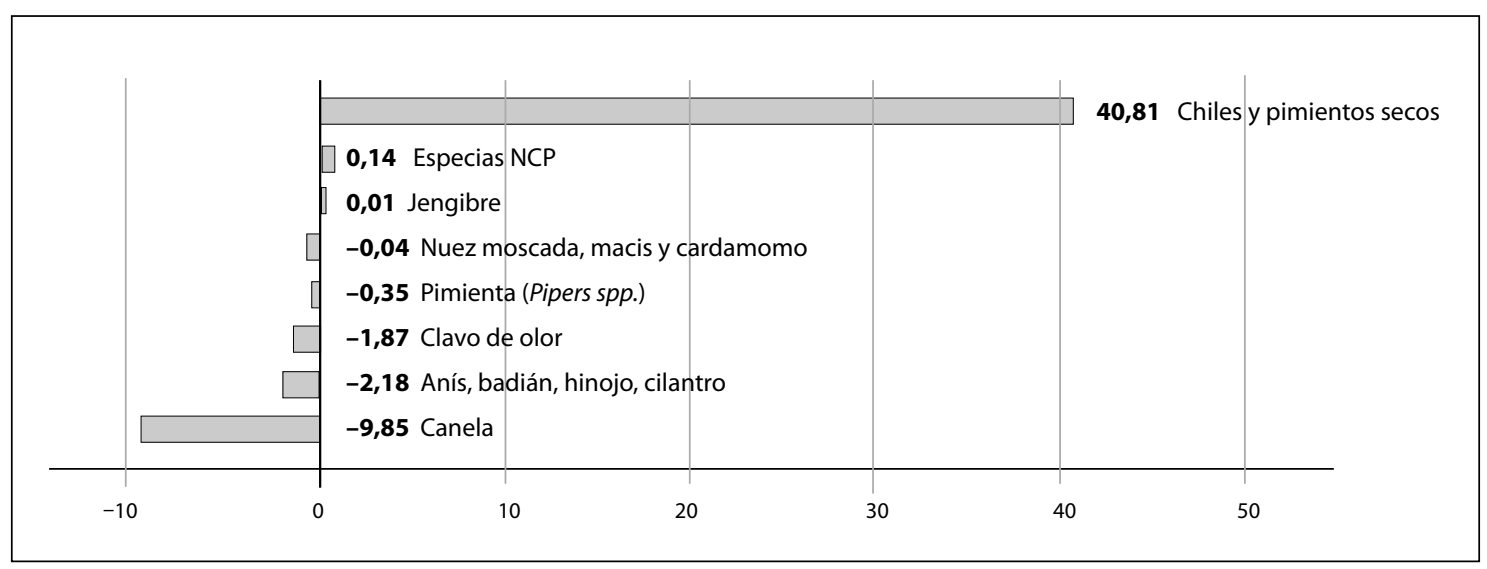

Fuente: Elaboración propia sobre la base de las estadísticas de FAOSTAT, 2005.

Gráfico 9

Los primeros productos agroindustriales del Perú con mayor IVCR en 2005, sector especias

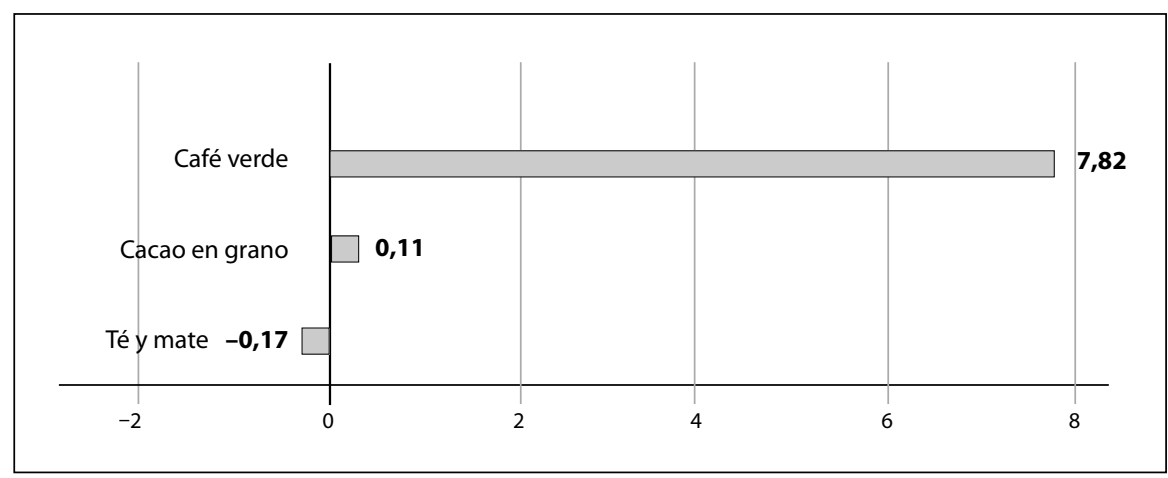

Fuente: Elaboración propia sobre la base de las estadísticas de FAOSTAT, 2005.

Gráfico 10

Los primeros productos agroindustriales del Perú con mayor IVCR en 2005, sector estimulantes

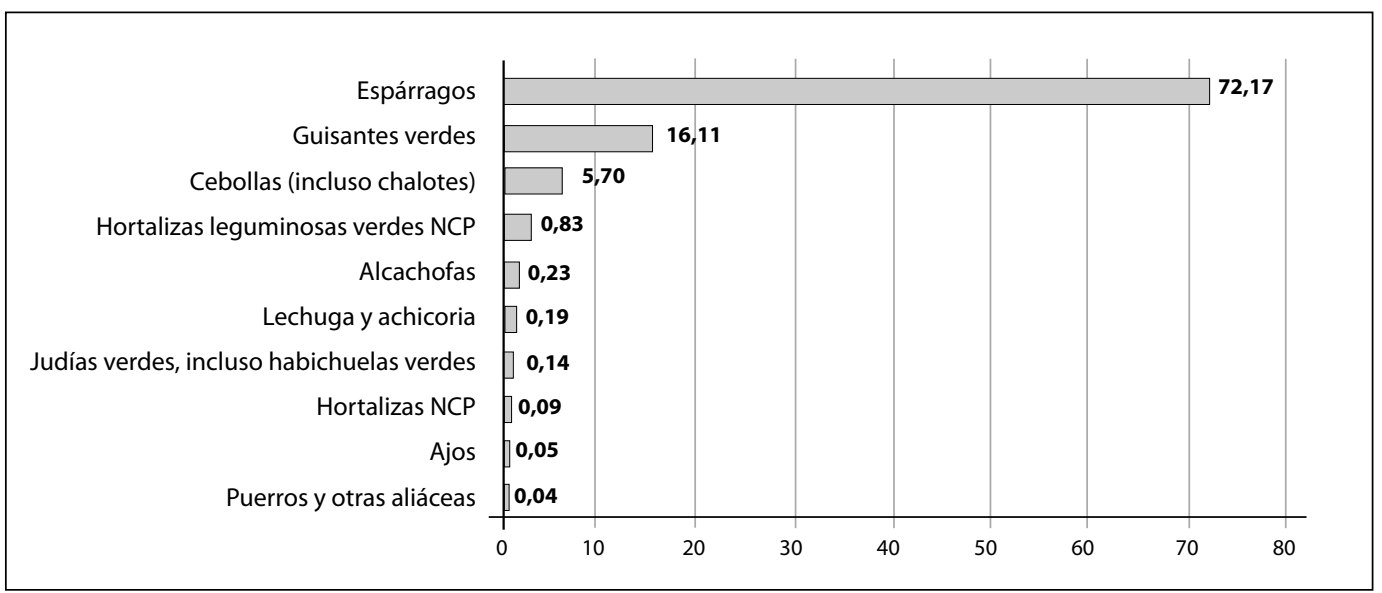

Fuente: Elaboración propia sobre la base de las estadísticas de FAOSTAT, 2005. 


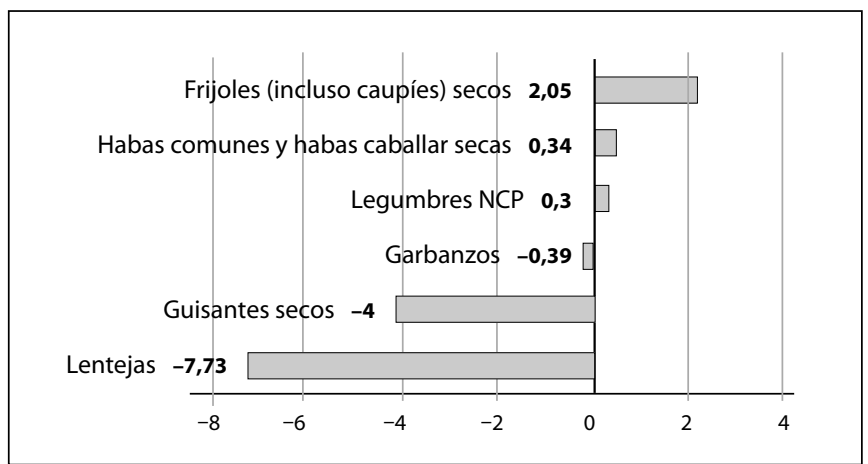

Fuente: Elaboración propia sobre la base de las estadísticas de FAOSTAT, 2005.

Gráfico 12

Los primeros productos agroindustriales del Perú con mayor IVCR en 2005, sector legumbres

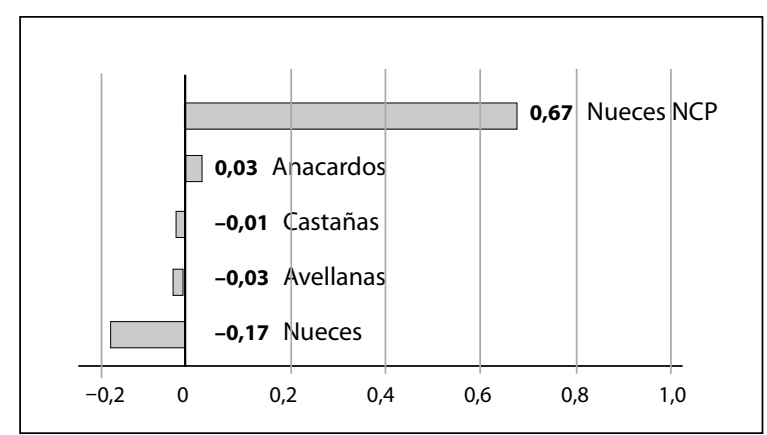

Fuente: Elaboración propia sobre la base de las estadísticas de FAOSTAT, 2005.

Gráfico 13

Los primeros productos agroindustriales del Perú con mayor IVCR en 2005, sector nueces

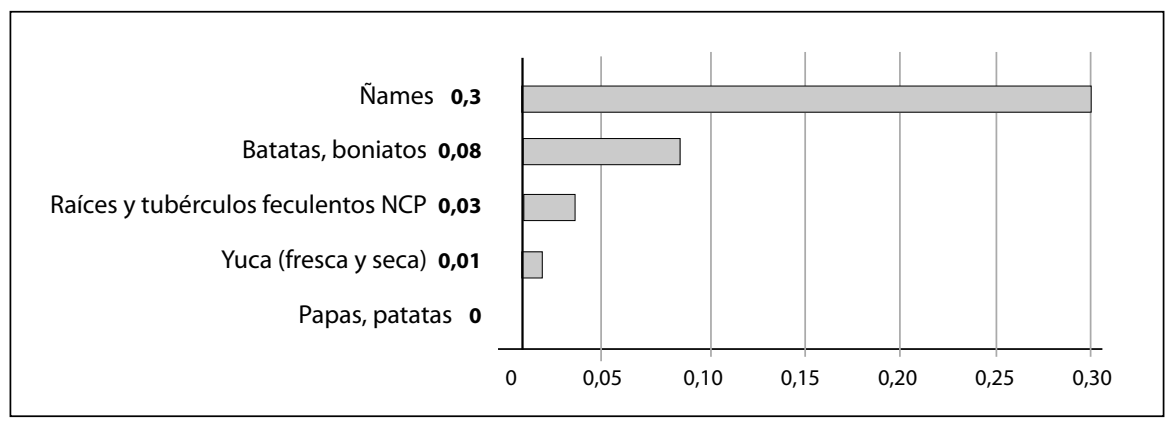

Fuente: Elaboración propia sobre la base de las estadísticas de FAOSTAT, 2005.

Gráfico 14

Los primeros productos agroindustriales del Perú con mayor IVCR

en 2005 , sector raíces feculentas 
De los resultados hallados en los gráficos 5 a 14, se observa que solo 11 productos tienen un IVCR mayor que uno (1), lo que es aproximadamente $13 \%$ de la oferta exportable agroindustrial peruana. El gráfico 15 muestra los productos que cumplen esta condición.

\section{Comparación y discusión de los resultados}

De los resultados de la sección anterior se puede determinar que solo $12 \%$ de los cultivos tienen cierta competitividad. De este grupo compuesto por 11 cultivos, únicamente 5 productos tienen un IVCR mayor que 10, lo cual los hace competitivos si solo se analiza al Perú, por lo que se puede impulsar aún más su exportación. Cabe destacar que el cálculo del IVCR para el Perú no había sido calculado anteriormente, lo que nos ha permitido analizar con objetividad el grado de competitividad de nuestra agroindustria.

Analizamos también la evolución del IVCR para los productos más importantes del norte del Perú, el cual muestra un comportamiento aleatorio, pero siempre positivo de tales productos, entre los que destaca el liderazgo de los espárragos. El gráfico 16 explica este comportamiento.

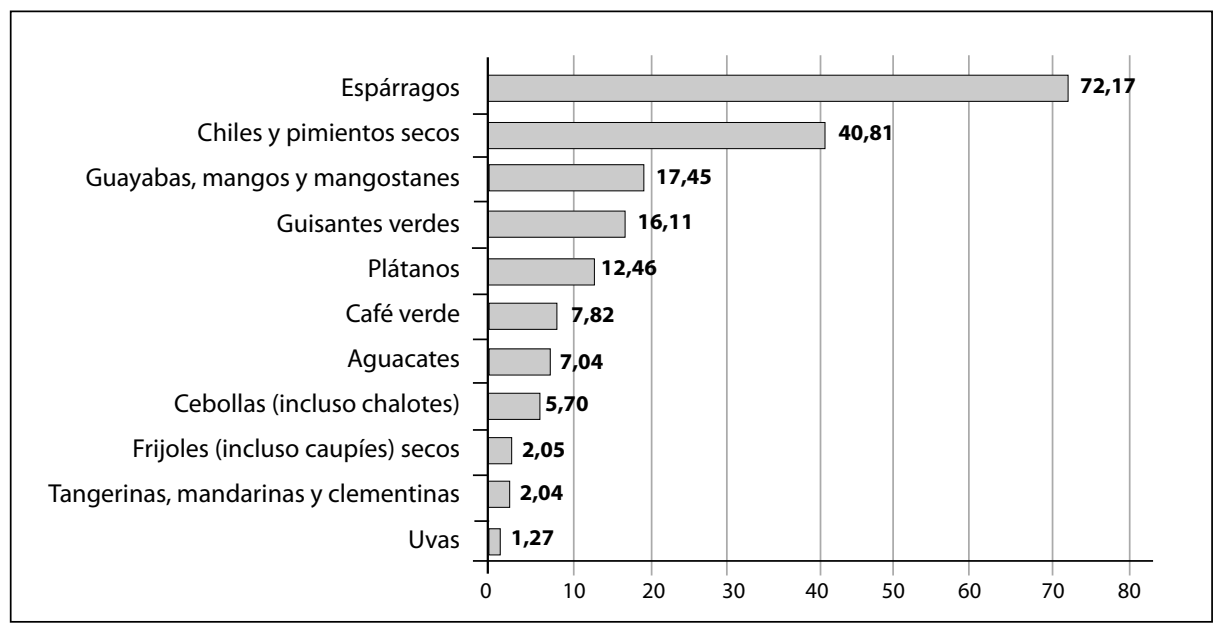

Fuente: Elaboración propia sobre la base de las estadísticas de FAOSTAT, 2005.

Gráfico 15

Productos agroindustriales del Perú con IVCR mayor que uno (1), en 2005

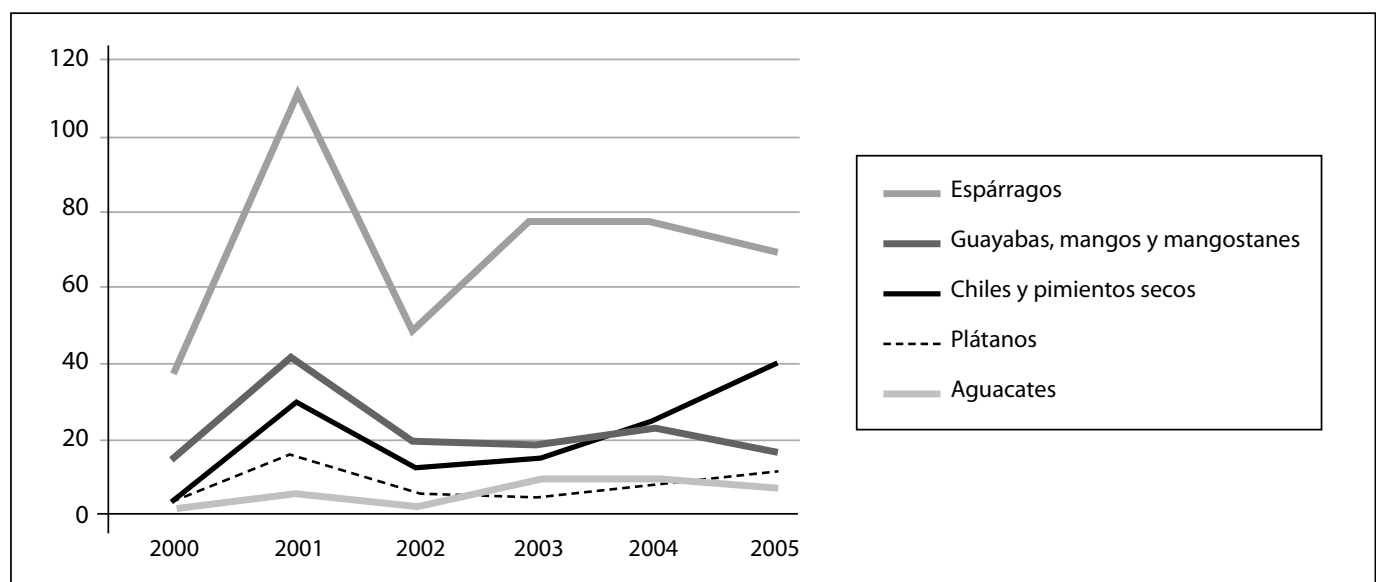

Fuente: Elaboración propia sobre la base de las estadísticas de FAOSTAT, 2005.

Gráfico 16

Evolución del IVCR en los principales productos del norte del Perú, 2000-2005 
Con la finalidad de analizar la brecha de competitividad, es decir, en cuánto se tiene que mejorar, se puede comparar la competitividad de los productos peruanos con los de Estados Unidos, pues también se tenía ad portas la aprobación del tratado de libre comercio entre el Perú y los Estados Unidos.

Para tal efecto se calculó la relación entre el IVCRPerú con el IVCR-Estados Unidos, obteniéndose los re- sultados que se muestran en el gráfico 17 , donde se observa que las exportaciones competitivas agroindustriales peruanas en frutas y hortalizas son más competitivas que las de Estados Unidos; porque los Estados Unidos es uno de los principales importadores de frutas y hortalizas, lo cual se observa en el gráfico 18.

Por otro lado, para saber cuánto nos falta mejorar en competitividad en el nivel latinoamericano se pue-

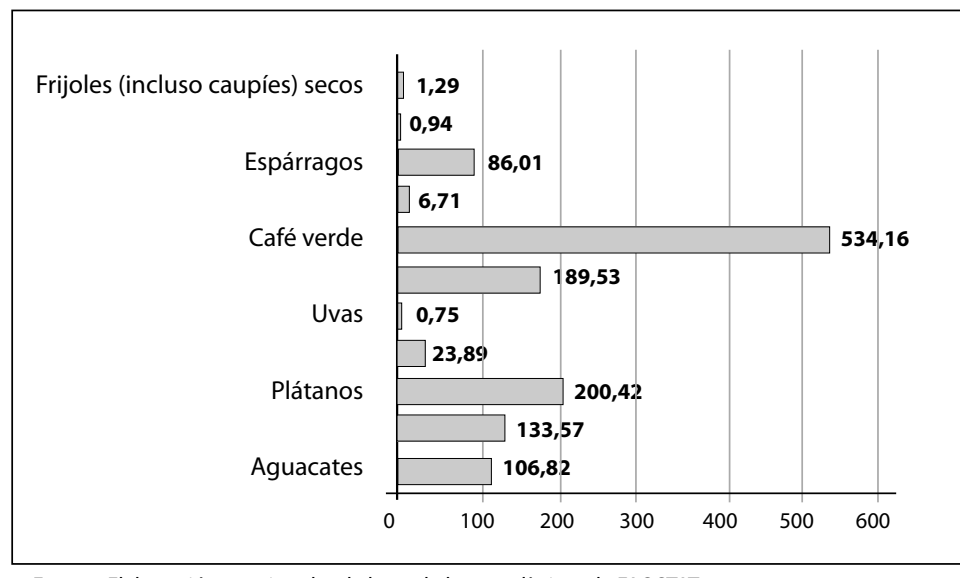

Fuente: Elaboración propia sobre la base de las estadísticas de FAOSTAT, 2005.

Gráfico 17

Comparación del IVCR del Perú frente al de Estados Unidos

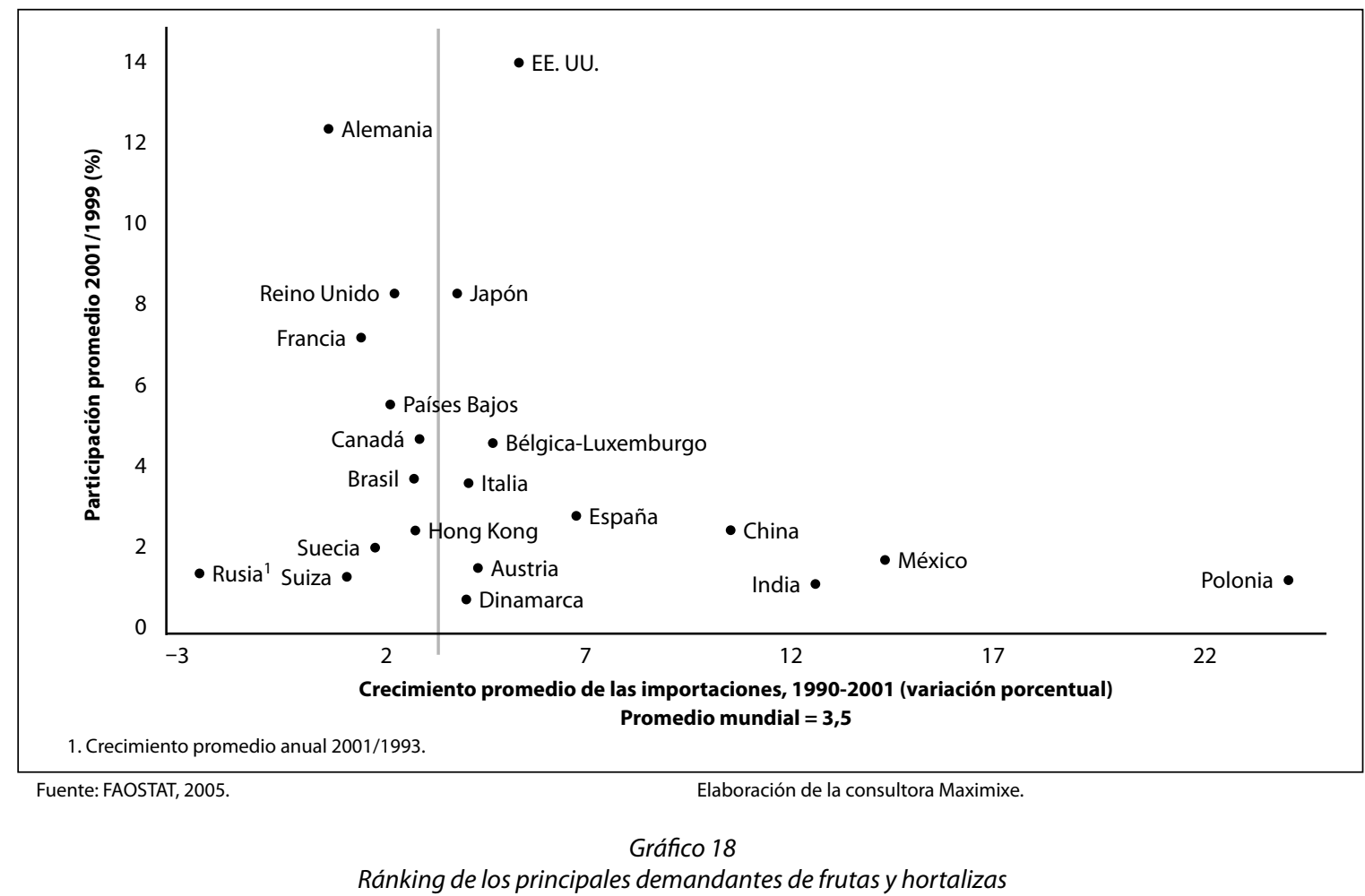

Cuad. Difus. 14 (26), jun. 2009 
de comparar con países líderes para cada producto. Con esta finalidad se realizó una comparación con el Brasil. El gráfico 19 muestra la relación del IVCR-Perú con el IVCR-Brasil para las principales exportaciones peruanas en la que se observa que algunos productos como el café pierden competitividad, es decir, muestran una relación negativa, y otros son competitivos, pero en un menor grado. Además, cabe resaltar que los cultivos como espárragos y paltas mantienen su ventaja competitiva. Se puede concluir que todavía se tiene que mejorar en competitividad.

Si se toma en cuenta que tradicionalmente Chile es uno de nuestros más importantes competidores en frutas y verduras para la exportación, en el gráfico 20 se muestra la comparación de algunos de los cultivos más competitivos del Perú y Chile. Nuevamente, los espárragos y los mangos ganan en ventaja competitiva. Esto se puede explicar por la ventaja comparativa del clima, el cual hace que nuestros productos ingresen en temporada única respecto de los demás países.

Con la finalidad de analizar las causas de la mayor competitividad comparada y determinar en qué radica esta para ciertos productos en relación con los países de América Latina estudiados, se ha realizado una correlación entre los precios de producción por tonelada y los valores del índice de competitividad revelada

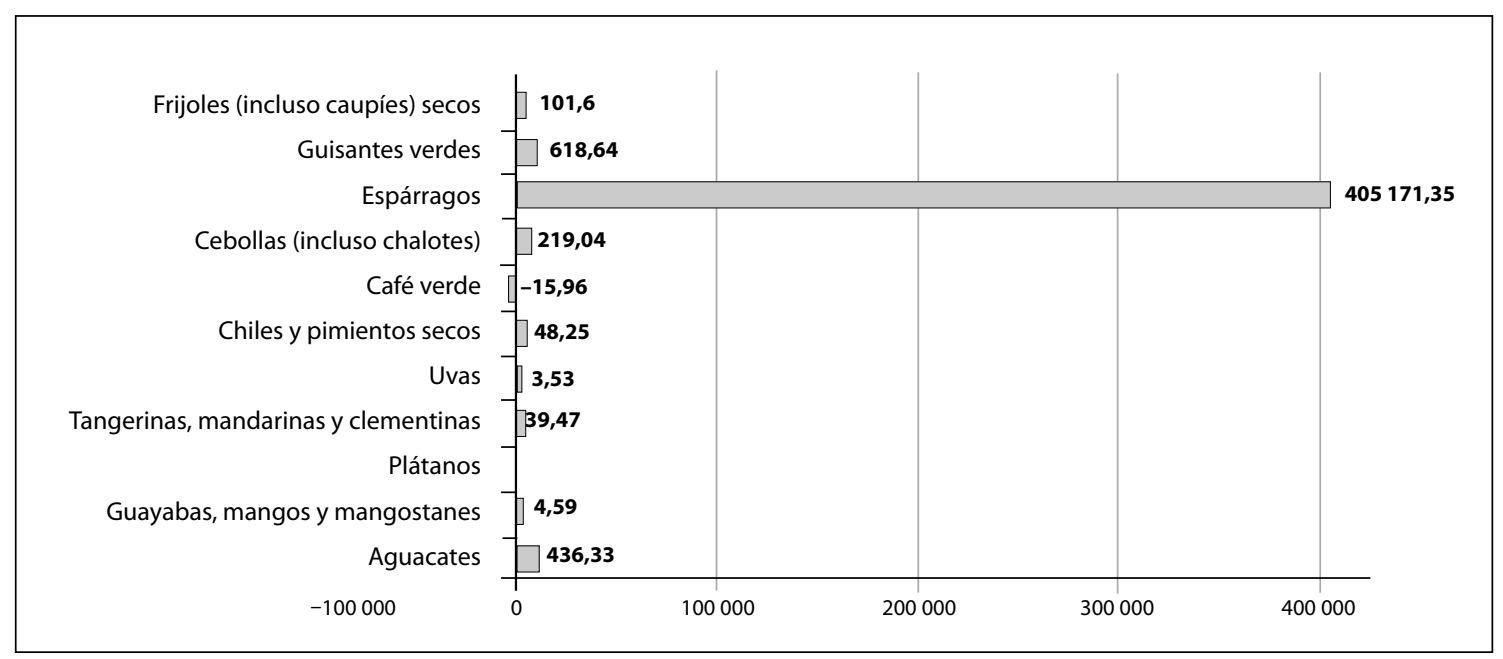

Fuente: Elaboración propia sobre la base de las estadísticas de FAOSTAT, 2005.

Gráfico 19

Comparación del IVCR del Perú frente al de Brasil

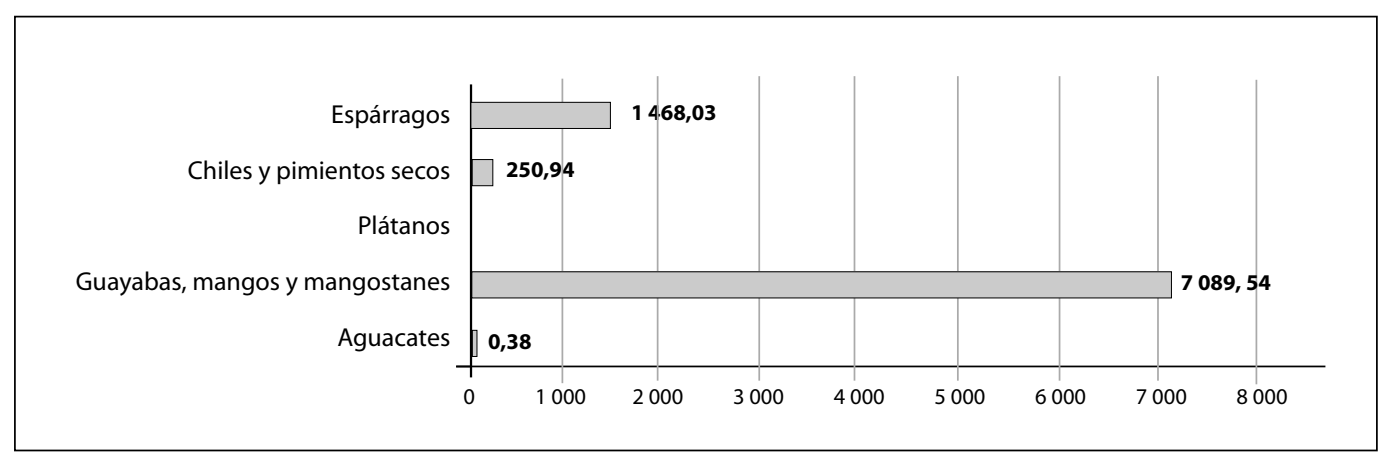

Fuente: Elaboración propia sobre la base de las estadísticas de FAOSTAT, 2005.

Gráfico 20

Comparación del IVCR del Perú frente al de Chile 
comparados. En el gráfico 21 se presentan los precios de producción por producto y por países, de manera que se puede observar que en los productos en los cuales el Perú tiene un mayor índice de ventaja comparativa también tiene un menor precio de producción, lo cual indica que la competitividad se debe mayormente al precio de los commodities; como también a haber logrado cierta especialización en los métodos de producción o mejores condiciones comparativas, específicamente suelo y clima.

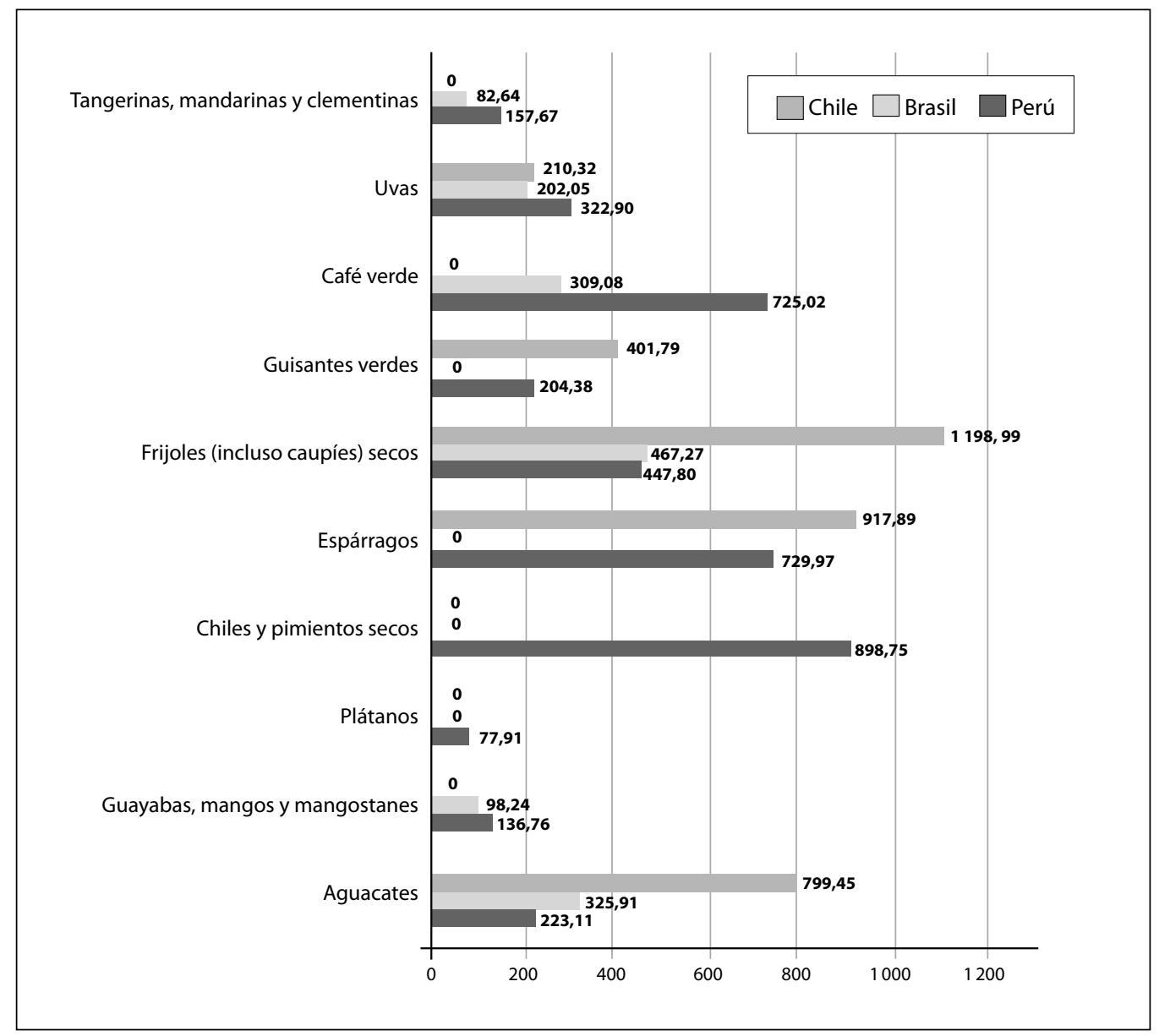

Fuente: Elaboración propia sobre la base de las estadísticas de FAOSTAT, 2005.

\section{Gráfico 2}

Comparación del índice de competitividad revelada según precio por producto y por país

\section{Determinantes de la competitividad}

Con el propósito de establecer cuáles son los factores que influyen en la competitividad de la región se realizó el análisis competitivo a través del modelo de Porter que es aplicable a un determinado país, región o cluster. En el gráfico 22 se identifican los factores que influyen en el modelo del diamante de Porter a través del análisis a las entrevistas con los principales representantes de los sectores público y privado. Los resultados se muestran a continuación: 


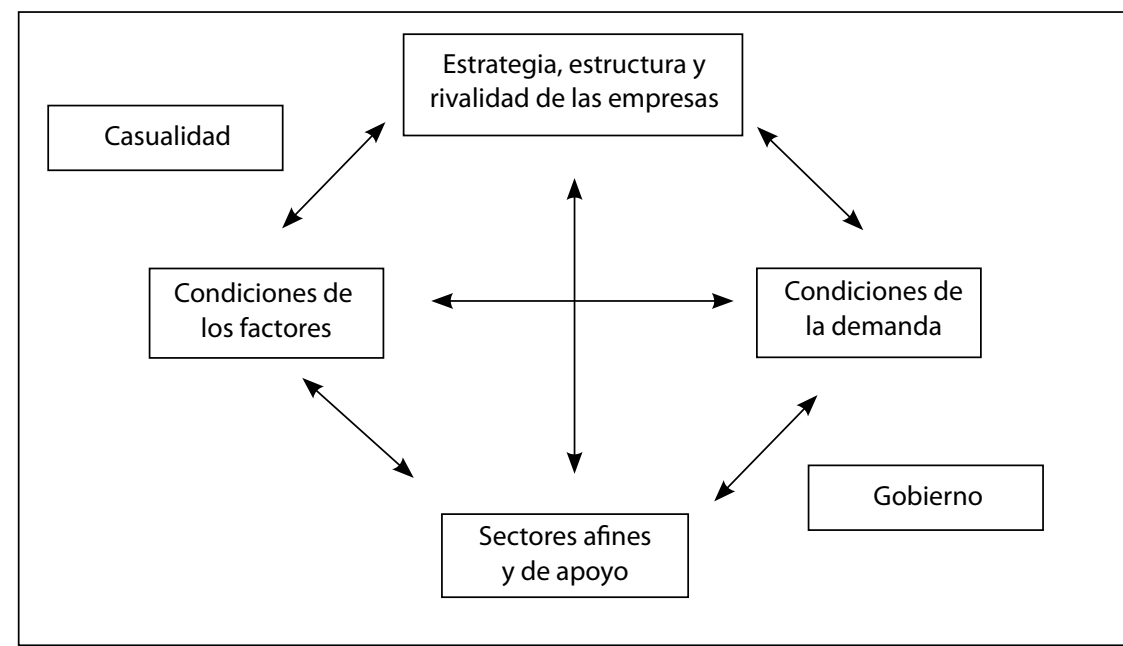

Fuente: Porter, 1990.

Gráfico 22

Diamante de Porter

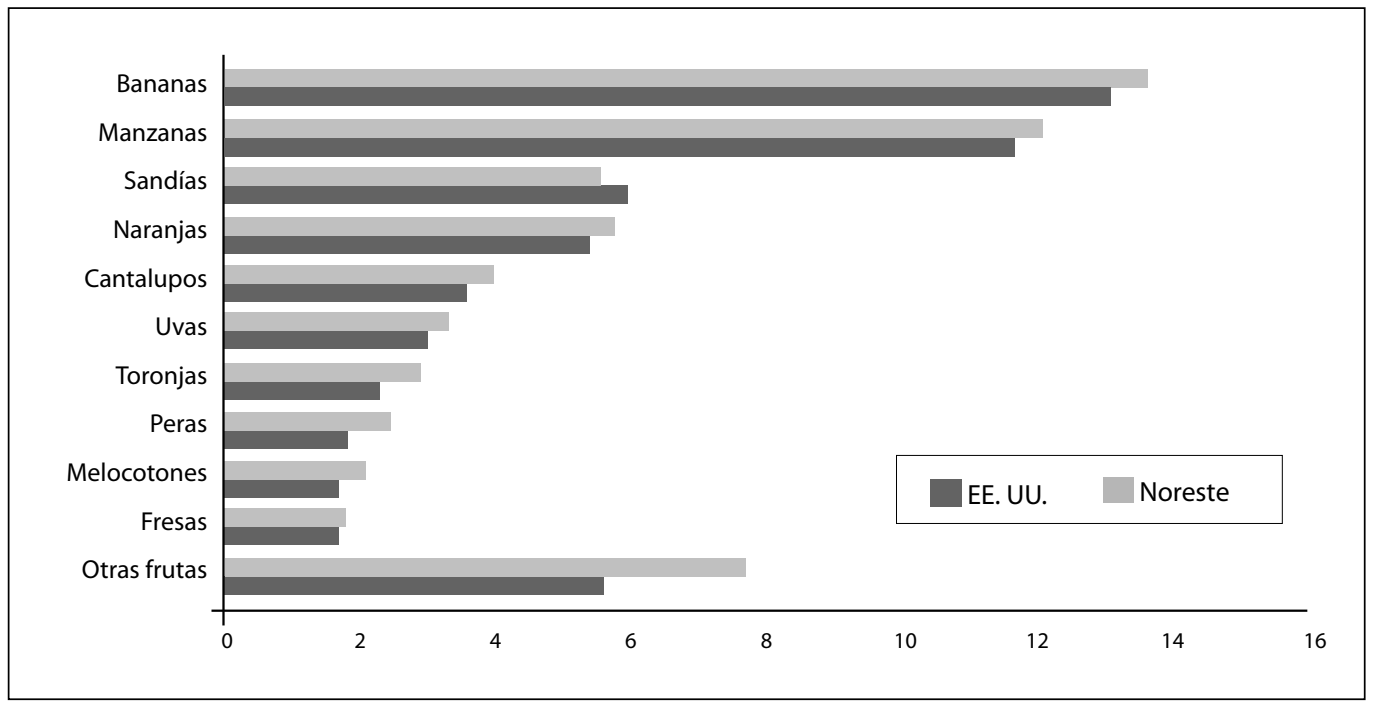

Fuente: Maximixe, 2005

Gráfico 23

Consumo per cápita de frutas frescas en los Estados Unidos y Noreste 


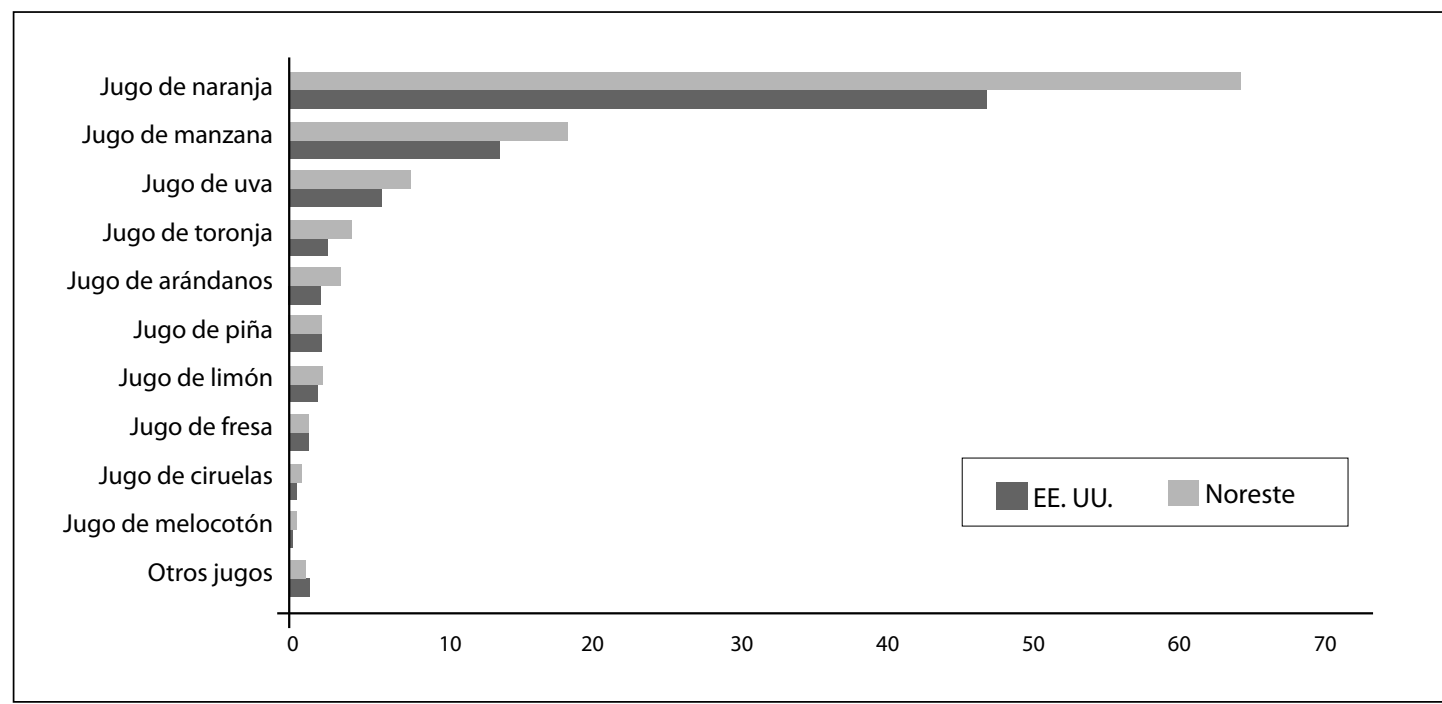

Fuente: Maximixe, 2005

Gráfico 24

Consumo per cápita de jugos de frutas en los Estados Unidos y Noreste

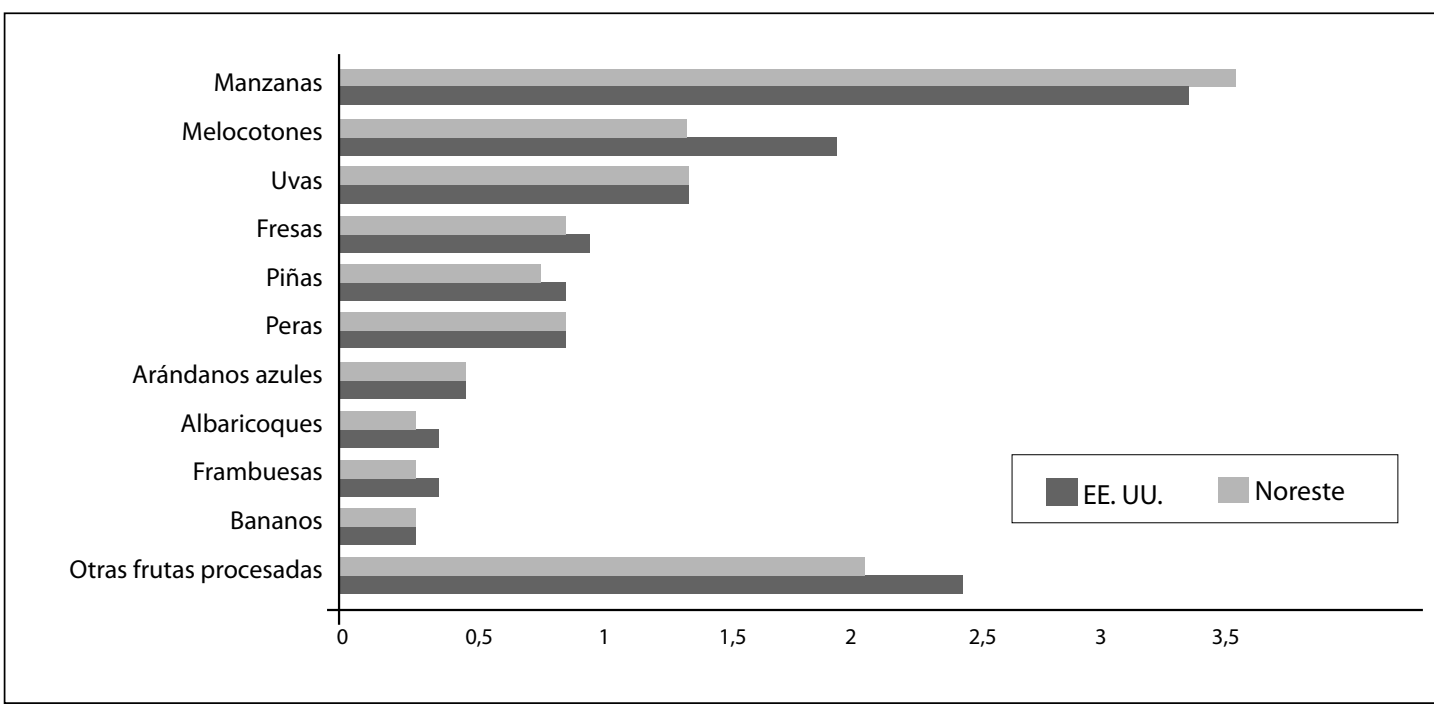

Fuente: Maximixe, 2005.

\section{Gráfico 25}

Consumo per cápita de frutas procesadas en los Estados Unidos y Noreste

- Condiciones de la demanda. El sector frutas y verduras está en crecimiento en el mundo, especialmente en Estados Unidos, como se muestra en los gráficos 23,24 y 25.

De los resultados hallados en los gráficos 23,24 y 25 se observa que las tendencias en el mercado son hacia lo natural y orgánico. Además, nuestra exportación es principalmente de productos primarios, lo cual indica que necesitamos incrementar el valor para el cliente.

Se observa también que la demanda local ha crecido por la aparición de cadenas de supermercados, las cuales están aumentando la demanda por frutas y vegetales, así como la exigencia de una mayor calidad por parte de los proveedores. 
- Sectores afines y de apoyo. Los proveedores son campesinos que poseen poca extensión de terreno y se aferran a los cultivos tradicionales como el arroz, el cual se ha mostrado como deficiente y poco competitivo, pues:

1) Existen muchos campesinos con poca extensión de terreno, lo que no hace posible el desarrollo de la asociatividad por la desconfianza entre ellos.

2) Las pocas empresas grandes exportadoras de la región establecen contratos de abastecimiento con algunos campesinos, incluyendo financiamiento y capacitación técnica.

3) Existe deficiencia logística: un solo terminal marítimo y los servicios de transporte aéreo encarecen el producto.

4) El agua es un recurso escaso y limita el crecimiento de la producción. Existen proyectos de irrigación en proceso.

5) Un tema importante es la limitación de energía en los campos de cultivo, lo que impide la extracción de agua del subsuelo.

6) Los costos de los fertilizantes ylos químicos para combatir las plagas son elevados.
- Condiciones de los factores. Falta de uso de la tecnología, especialmente en el desarrollo de la biogenética. En los gráficos 26 y 27 se muestra el estado de la biotecnología en el Perú en comparación con los países de América Latina, según FAO. En estos gráficos se observa que el Perú tiene muy poco desarrollo tecnológico en biotecnología, pues la mayoría solo se queda en la fase de proyecto, sin llegar, por ejemplo, a la comercialización de patentes. Estas son algunas razones:

1) Poco desarrollo de inteligencia de mercado $y$ falta de información actualizada de tendencias de consumo.

2) Falta de tecnificación de los sistemas de riego a riego por goteo.

3) La mayoría de empresas del sector no cuenta con certificación internacional de calidad o, en su defecto, están en procesos de certificación de normas, como la ISO-9001.

4) Especialmente en la costa norte del Perú, existe un deficiente servicio logístico en cuanto a infraestructura, costos de operación y tiempo de entrega.

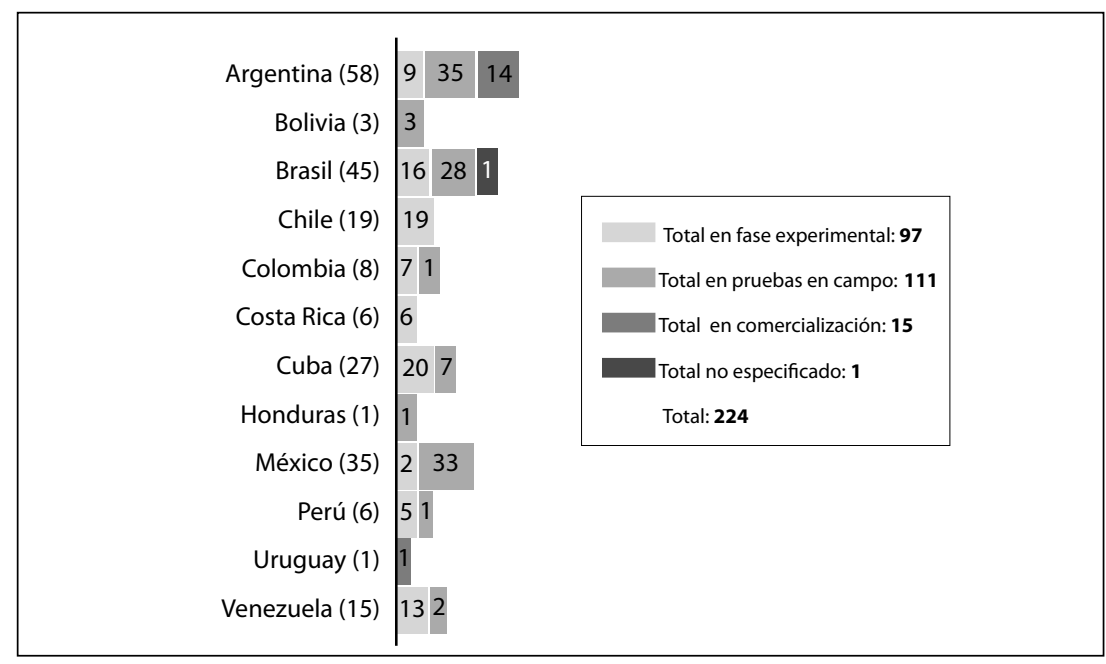

Fuente: Estadísticas de FAOSTAT, 2005. 


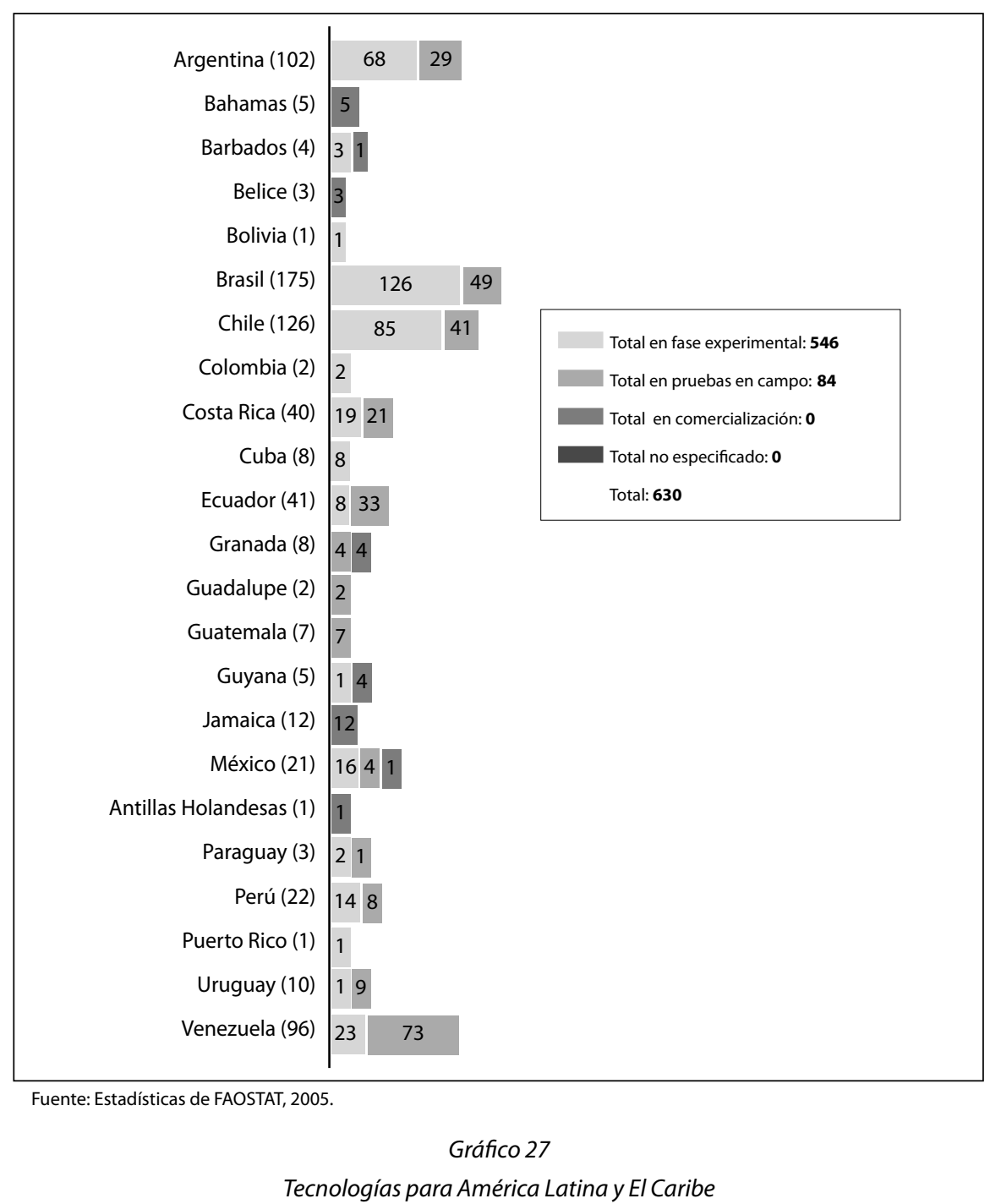

Como parte de las condiciones de los factores, en los gráficos 28 y 29 se presenta el índice de desempeño logístico (Logisitc performance index, LPI) del Perú, el cual es comparado con el país líder de Latinoamérica en este rubro. No obstante, tenemos ventajas comparativas de suelo y clima que se pueden explotar más.

- Estrategia, estructura y rivalidad de las empresas. No existe desarrollo de clusters, pues son pocas las empresas que realizan agroexportación y no existe mucha rivalidad entre ellas. Las más importantes empresas operan mediante una estrategia comercial y mantienen sedes comerciales en los mercados extranjeros. Aunque se están impulsando las cadenas productivas, especialmente, en los cultivos del maíz y el arroz.

- Casualidad. Existe el riesgo de la aparición cíclica del Fenómeno El Niño, el cual puede originar daños en los cultivos de exportación de la costa norte del Perú.

- Gobierno. El gobierno regional ha creado un Consejo Regional de Competitividad, el que viene impulsando las coordinaciones entre el Estado y el sector privado para la promoción de las inversiones. No obstante, su poder de convocatoria es muy débil, pues ha perdido credibilidad por el incumplimiento de sus promesas. 


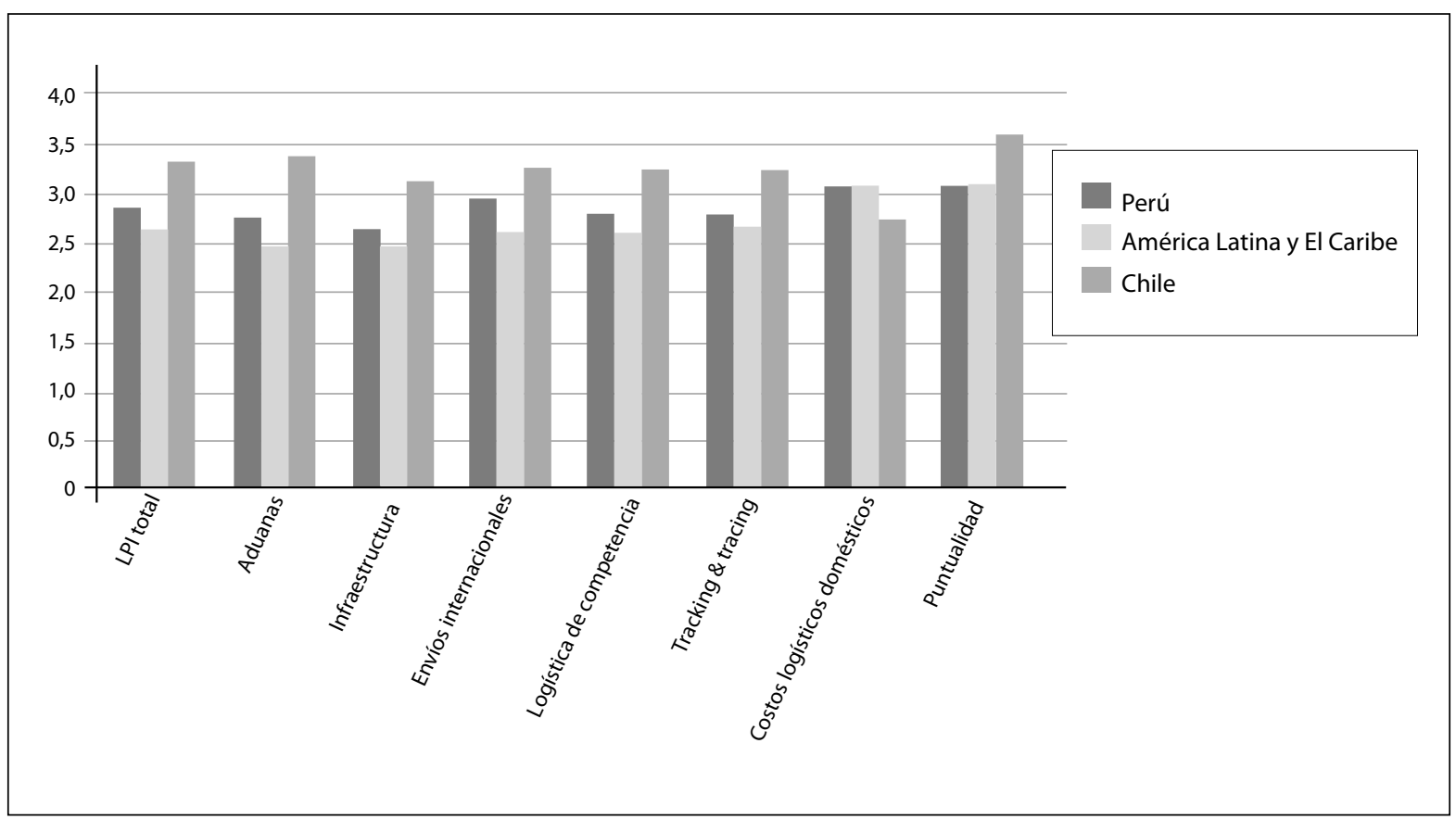

Fuente: Elaboración propia sobre la base de las estadísticas del Banco Mundial.

\section{Gráfico 28}

Comparación del índice de desempeño logístico (LPI) según la puntuación por país (diagrama de barras)

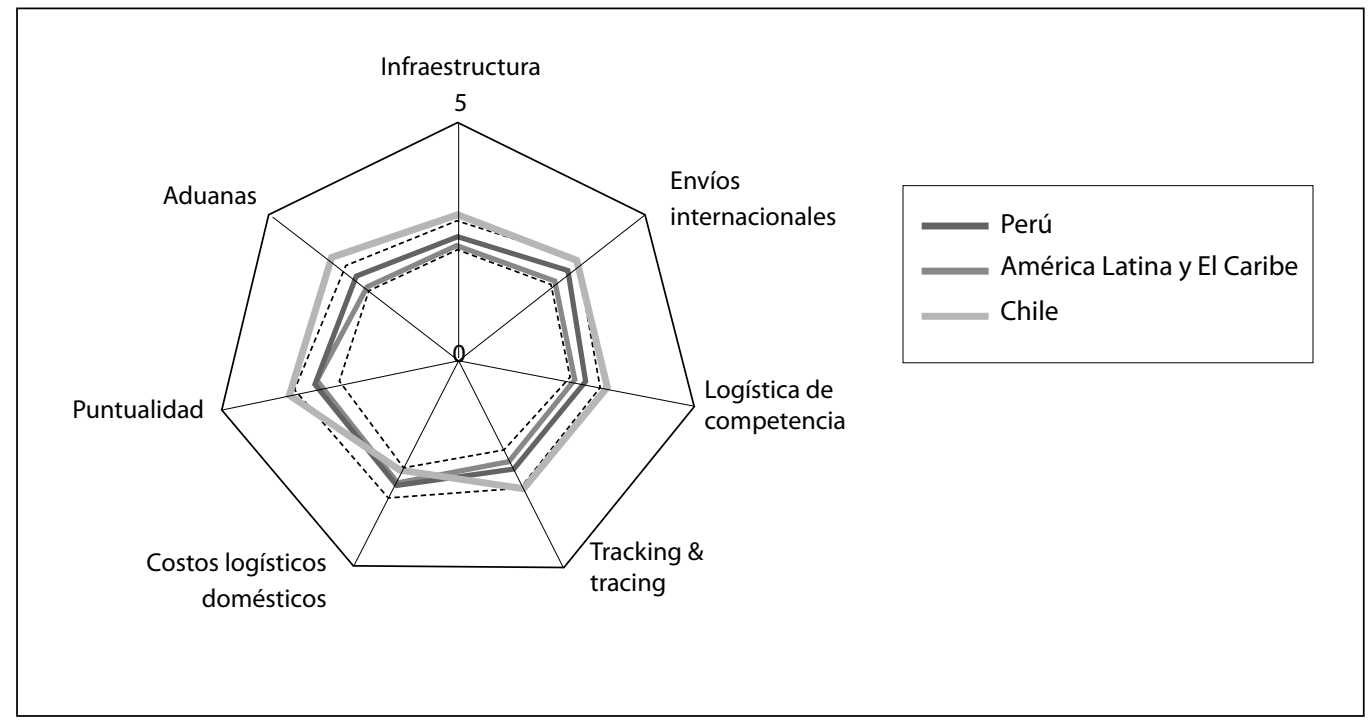

Fuente: Elaboración propia sobre la base de las estadísticas del Banco Mundial.

Gráfico 29

Comparación del índice de desempeño logístico (LPI) según la puntuación por país (diagrama radial) 
Además, el gobierno central en coordinación con la CAF y con la ejecución de la empresa brasileña Odebrecht, está construyendo la última etapa del proyecto hidroenergético de Olmos, en la Región Lambayeque.

\section{CONCLUSIONES GENERALES}

- Se ha encontrado un método numérico basado en la teoría de la integración económica, es decir, que el índice de ventajas competitivas reveladas (IVCR) permite medir el grado de competitividad de los cultivos de exportación de la Región Lambayeque.

- Dentro de los cultivos más competitivos están: aguacates o paltas, plátanos, mangos, espárragos, pimientos secos y café. No obstante, al compararlos con otros países latinoamericanos como Chile y Brasil, solo los espárragos y los mangos mantienen una competitividad sólida.

- El índice de ventajas competitivas reveladas indica también qué cultivos no son competitivos y, por lo tanto, deben importarse. Dentro de estos cultivos está el arroz, el cual es un cultivo tradicional que debe sustituirse.

- Los productos de exportación son en su mayoría commodities. La mayor parte de las ventajas competitivas se deben al menor precio de producción o por ventajas comparativas como el suelo y el clima. Existen muy pocas empresas agroexportadoras en la región que den un mayor valor agregado a la expor- tación de productos agroindustriales, aunque solo a través de la marca y la mejora de los envases.

- Según las estadísticas y los datos mostrados por la $\mathrm{FAO}$, se tiene muy poco desarrollo tecnológico, pues se nota una falta de gestión tecnológica, también la mayoría de proyectos de tecnología se queda en la fase de diseño y no llega a la comercialización de las patentes.

- A pesar de todas las dificultades anteriormente mencionadas, se puede tener un punto de vista más optimista al considerarlas como oportunidades para poder invertir y generar mayor competitividad. Por ejemplo, ahora que el Perú tiene una calificación de riesgo-país de grado de inversión su competitividad ha mejorado, especialmente por su estabilidad y crecimiento económico en medio de la crisis financiera internacional. El sector agroindustrial es un sector económico de mucho potencial que ahora puede hacer realidad su crecimiento con mayor competitividad, especialmente, mediante una mayor inversión.

- La economía estadounidense, a pesar de su crisis financiera, está ávida de nuestros productos, pero tan solo $12 \%$ de todos ellos son explotados. Necesitamos tecnología para los cultivos, el riego tecnificado y el desarrollo de clusters para aumentar nuestra competitividad.

- Finalmente, tal como se muestra en el gráfico 30, se propone la creación de los siguientes clusters agroexportadores en la Región Lambayeque. 


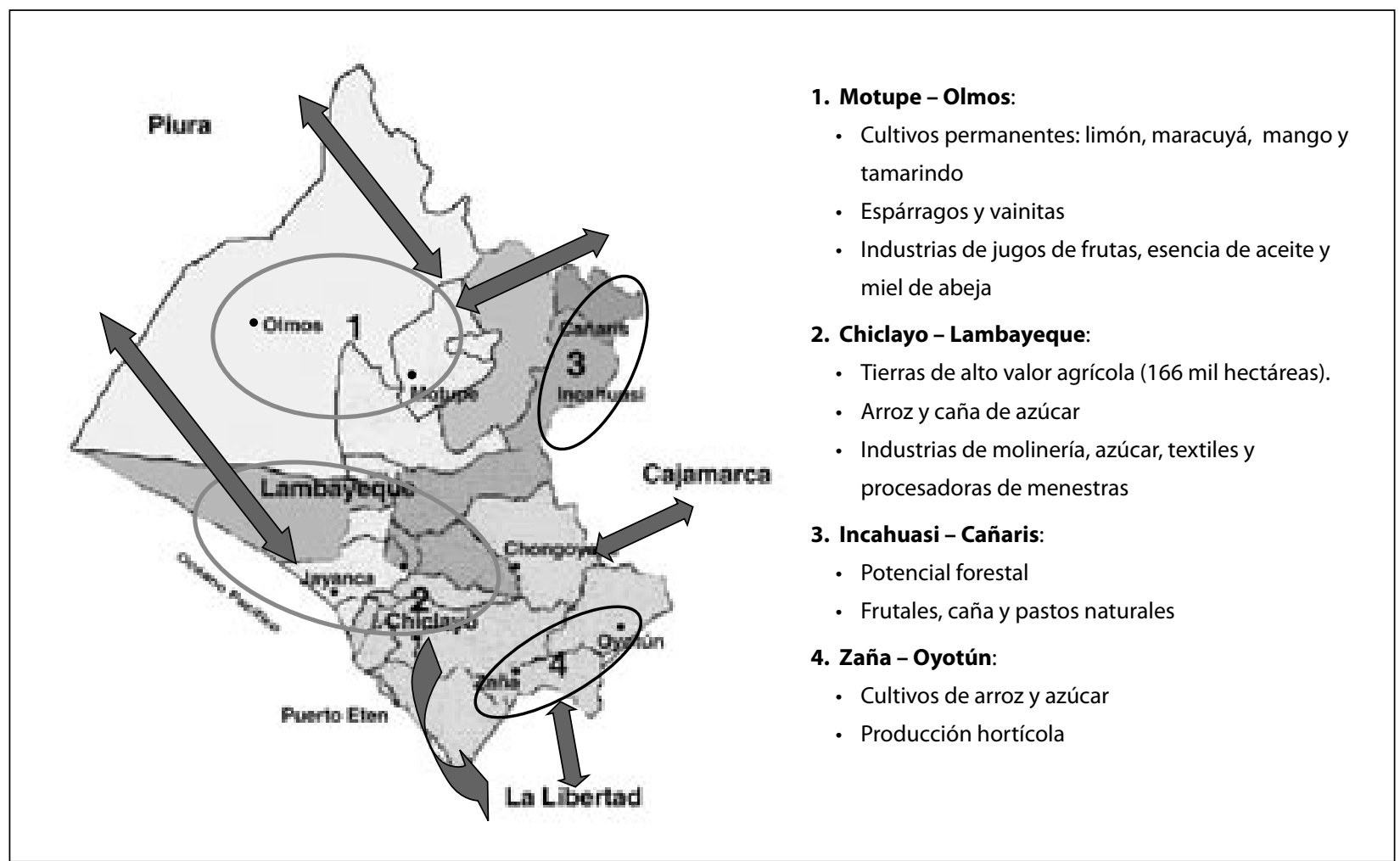

Fuente: Maximixe, 2005.

Gráfico 30

Propuesta de clusters agroexportadores en la Región Lambayeque, Perú 


\section{Referencias bibliográficas}

Ali, A. J. (1992). How to manage for international competitives. New York: International Business Press.

Antoine, Patrick Alphonsus. (1992). Modelling international competitiveness: an econometric approach. University of Florida.

Aquino, N. R. (1991). Constant improvement: a strategic imperative. Business and Economic Review, 37 (4), 18-21.

Balassa, Bela. (1965). Trade liberalization and revealed comparative advantage. The Manchester School of Economics and Social Science, 33, 99-123.

Balassa, Bela. (1979). The changing pattern of comparative advantage in manufactured goods. The Review of Economics and Statistics, 61 (2), 259-266.

Bowman, C. (1992). Charting competitive strategy. En D. Faulkner \& G. Johnson. (eds.). The challenge of strategic management. London: Kogan Page.

Burgelman, R. A. \& Maidique, M. A. (1988). Strategic management of technology and innovation. Irwin: Homewood.

Buzzel, R. D. \& Gale, T. G. (1987). The PIMS principles linking strategy to performance. New York: The Free Press.

Calderón, César \& Serven, Luis. (2004). The effects of infrastructure developments on growth and income distribution. Santiago: Banco Central de Chile. Working Paper.

Casas T., Carlos. (2005). Indicadores regionales de competitividad regional. Lima: Consejo Nacional de Competitividad.

Castiglione, Ezio. (1999). The European agro-food system and the challenge of global competition. Roma: International Food and Agribusiness Management Association (ISMEA).

Corporación Andina de Fomento (CAF). (2007). Programa de apoyo a la competitividad (PAC). <http://pac.caf.com/ search.asp?qr=t\%C3\%A9>.

FAOSTAT. (2005). Food and Agriculture Organization of the United Nations (FAO). Organización de las Naciones Unidas para la Agricultura y la Alimentación <http:// www.fao.org>.
Fay, Marian \& Morrison, Mary. (2005). Infrastructure in Latin America and Caribbean: recent developments and key challenges. Washington, D.C.: The World Bank.

Feurer, Rainer \& Chaharbaghi, Kazem. (1994). Defining competitiveness: a holistic approach. Management Decision (MCB University Press Limited), 32 (2), 49-58.

Grant, R. M. (1992). Contemporary strategic analysis: concepts techniques, applications. Cambridge, MA: Basil Blackwell.

Hedley, B. (1977). Strategy and the business portfolio. Long Range Planning, 10 (1), 9-15.

IMD's World Competitiveness Center \& Centrum-PUCP. (2008). The world competitiveness yearbook 2008. Ránking mundial de competitividad 2008. Lima: IMD's World Competitiveness Center y Centrum-PUCP.

Johnson, G. \& Scholes, K. (1993). Exploring corporate strategy. New York: Prentice Hall.

Joy Way, Rosa. (2004). Cómo establecer prioridades en las regiones del Perú: una propuesta de índice de competitividad regional sostenible. Lima: CIES y CIPCA.

Kennedy, P. Lynn, Harrison, R., Wes, Kalaitzandonakes, Nicholas G., Peterson, Christopher \& Rindfuss, Ronald P. (1997, July-August). Perspectives on evaluating competitiveness in agribusiness industries. Agribusiness, 13 (4), 385-392.

Ketels, Christian H. M. (2007). Cluster and competitiveness in the global economy. Cambridge, MA: Harvard Business School, Institute for Strategy and Competitiveness.

Klother, P. (1988). Marketing management. New Jersey, Englewood Cliffs: Prentice-Hall.

Messner, Dirk \& Meyer-Stamer, Jörg. (1994, setiembre-octubre). Competitividad sistémica: pautas de gobierno y desarrollo. Nueva Sociedad, 130, 72-87.

Musik, Guillermo \& Romo, David M. (2004). Sobre el concepto de competitividad. México D.F.: Universidad Autónoma Metropolitana de México. Working Paper.

Piedra, Mario A., Kennedy, P. L. \& Harrison, W. (s/f). Hacia un marco conceptual para evaluar la competitividad de 
la pequeña y mediana agroindustria. CATIE. <http:// www.redepapa.org/piedra.pdf>.

Piercy, N. (1991). Market-led strategic change. London: Thorsons.

Porter, Michael. (1980). Competitive strategy. New York: The Free Press.

Porter, Michael. (1983). The technological dimension of competitive strategy. Research on Technological Innovation, Management and Policy, 1, 1-33.

Porter, Michael. (1985). Competitive advantage. New York: The Free Press.

Porter, Michael. (1990). The competitive advantage of nations. New York: The Free Press.

Rappaport, A. (1987). Creating shareholder value: The new standard for business performance. New York: The Free Press.
Robinson, S. J. Q., Hichens, R. E. \& Wade, D. P. (1978). The directional policy matrix-tool for strategy planning. Long Range Planning, 11(3), 8-15.

Slack, N. (1991). The manufacturing advantage. London: Mercury Books.

Stalk, G. (1992). Timed based competition and beyond: Competing on capabilities. Planning Review, 20 (5). 9-27.

Van Rooyen, C. J., Esterhuizen, D. \& Doyer, O. T. (2000). How competitive is agribusiness in the South African food commodity chain. En J. H. Trienekens \& P. J. P. Zuurbier (eds.), Chain management in agribusiness and the food industry. Wageningen The Netherlands: Wageningen Academic Publishers.

Vollrath, T. L. (1991, junio). A theoretical evaluation of alternative trade intensity measures of revealed comparative advantage. Review of World Economics, 127 (2), 265-280. 
